\title{
Performance Investigation of Membrane Bioreactor Systems During Municipal Wastewater Reclamation
}

\author{
James F. DeCarolis Jr. *, Samer Adham
}

\begin{abstract}
Four commercially available membrane bioreactor (MBR) systems were operated at the pilot scale, to investigate performance during the reclamation of municipal wastewater. The MBR performance was evaluated under a variety of operating conditions, including two types of feed wastewater (raw and advanced primary effluent), hydraulic retention times (HRTs) ranging from 2 to 6 hours, and permeate fluxes between 20 and $41 \mathrm{lmh}$. Test results showed that MBR systems were capable of operating on advanced primary effluent, despite the possible presence of coagulant and/or polymer residual, with minimal membrane fouling. Membrane performance data generated during this study was also used to quantify the relationship between permeate flux and membrane fouling. Cleaning intervals at various flux conditions were estimated as follows: 69 days at $20 \mathrm{lmh}, 58$ days at $25 \mathrm{lmh}$, and 30 days for operation between 31 and $41 \mathrm{lmh}$. It was also demonstrated that the MBR process could be optimized to operate with minimal fouling under high hydraulic (flux $=$ $37 \mathrm{lmh}$ ) and organic loading (HRT $=2$ hours and food-to-microorganism ratio $=0.33 \mathrm{~g} \mathrm{COD} / \mathrm{g}$ VSS $\cdot \mathrm{d})$ conditions. Water quality monitoring conducted throughout the study showed that each MBR system consistently produced an oxidized (5-day biochemical oxygen demand $<2 \mathrm{mg} / \mathrm{L}$ ) and nitrified (ammonia $<1 \mathrm{mg}-\mathrm{N} / \mathrm{L}$ ) effluent low in particulate matter (turbidity $<0.1$ NTU), under all conditions tested. Water Environ. Res., 79, 2536 (2007).
\end{abstract}

KEYWORDS: membrane bioreactors, membrane processes, water reclamation, water reuse, reclaimed water, wastewater treatment, municipal wastewater.

doi: $10.2175 / 106143007 \mathrm{X} 212184$

\section{Introduction}

The application of membrane bioreactor (MBR) technology to treat municipal wastewater for reuse purposes is gaining momentum on a worldwide basis (Daigger et al., 2005). This technology, which combines conventional activated sludge treatment with lowpressure membrane filtration, is attractive to water reuse planners and providers because of its small footprint requirement, ability to produce consistent/high-level effluent water quality, and minimal need for operator attention (Adham and DeCarolis, 2004). Such characteristics also make MBR systems ideal for satellite treatment applications, where wastewater is treated remotely to meet nearby reuse needs. Benefits of these facilities include avoidance of expanding antiquated centralized wastewater treatment systems and negating the cost of conveying reclaimed water long distances to where its needed (Guendert and Jordan, 2004).

MWH Americas Inc., San Diego, California.

* MWH Americas Inc., 9444 Farnham Street, Suite 300, San Diego CA 92117; e-mail: james.decarolis@mwhglobal.com.
Because of the rapidly increasing number of municipal wastewater MBR applications, it is crucial to gain a better understanding of how various operating conditions can affect performance. Key operating parameters for MBR processes include solids retention time (SRT), hydraulic retention time (HRT), food-to-microorganism (F/M) ratio, and membrane permeate flux. A survey of full-scale MBR plants (Adham and Gagliardo, 1998) revealed the following typical values for each of these parameters: SRT $>30$ days, membrane permeate flux (continuous) $=25 \mathrm{lmh}$, HRT $=20$ hours, and $\mathrm{F} / \mathrm{M}<0.1$ day $^{-1}$. However, recent studies suggest that MBRs can operate with limited success under more efficient conditions, including the following: HRT of 1.5 to 5 hours (Adham et al., 2000; Aguilera et al., 2003; Holler and Trosch, 2001); SRTs $<10$ days (Cicek et al., 2001; McInnis, 2003); permeate flux up to $60 \mathrm{lmh}$ (van der Roest et al., 2002); and F/Ms between 0.34 and $0.74 \mathrm{~g} \mathrm{COD} / \mathrm{g}$ VSS·d (Trussell et al., 2006). Further research is necessary to determine the limitations of these design parameters to provide guidelines to the wastewater reclamation industry.

Another important factor in MBR performance is feed wastewater quality. To date, the application of MBR systems for municipal wastewater reclamation has focused on the treatment of two sources of wastewater-raw wastewater and primary effluent. Another potential source of reclaimed water is advanced primary effluent. Advanced primary treatment differs from primary wastewater treatment, in that it typically includes the addition of coagulants and/or polymers for solid and organic removal. Some of the potential benefits of operating MBR systems on advanced primary effluent, as opposed to raw wastewater, include the following: reduction of process air requirements resulting from reduced organic loading, less occurrences of changes in water quality, lower prescreen maintenance requirements, and reduced footprint. A major drawback to operation on advanced primary effluent is the potential for chemical addition (particularly organic polymers) to negatively affect the performance of the membranes. The potential effects of these chemicals on MBR performance have not been previously studied.

The main intent of this study was to investigate the effect of various operating conditions on the performance of MBR systems during the reclamation of municipal wastewater. This was accomplished by operating MBR pilot systems from four different suppliers-US Filter (Warrendale, Pennsylvania), Kubota Corporation (Osaka, Japan), Zenon Environmental Inc. (Oakville, Ontario), and Mitsubishi Rayon Corporation (Tokyo)—during a 16-month period. During this time, MBR performance was evaluated under a variety of operating conditions, including two types of feed wastewater (raw and advanced primary effluent), HRT between 


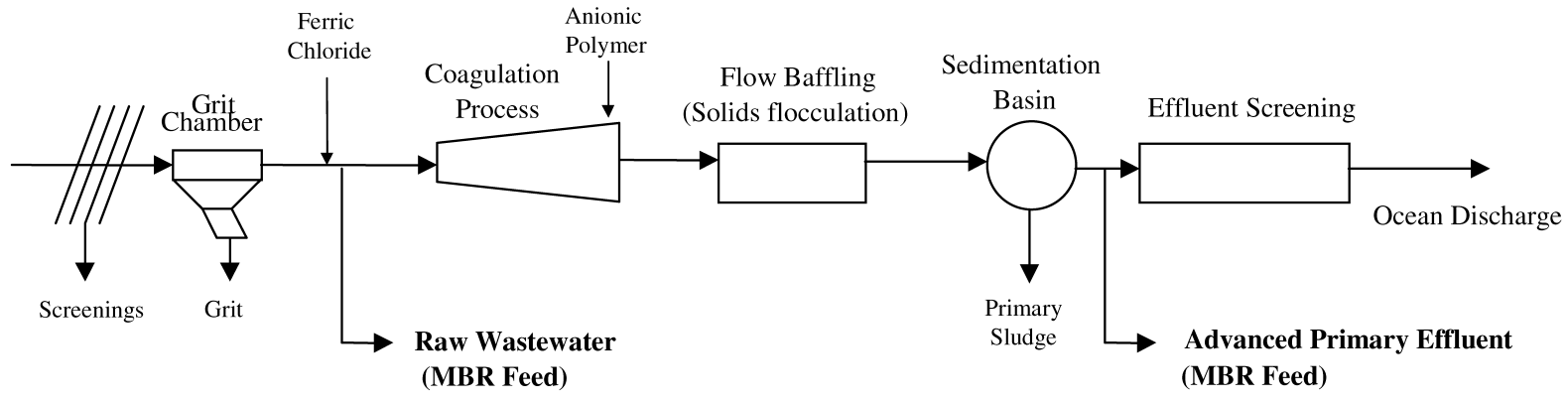

Figure 1-Schematic diagram of the PLWTP.

2 and 6 hours, and permeate fluxes ranging from 26 to $41 \mathrm{lmh}$. The MBR performance was assessed by monitoring the productivity, measured by specific flux under steady operating conditions. An extensive water quality sampling plan was also implemented at the onset of the study, to assess the ability of MBR systems to remove particulate, organic, nutrient, and microbial contaminants.

\section{Materials and Methods}

Source Water. The source water for this study was municipal wastewater from the Point Loma Wastewater Treatment Plant (PLWTP) located in San Diego, California. This $950000-\mathrm{m}^{3} / \mathrm{d}$ advanced primary treatment facility is the backbone of municipal wastewater treatment for the City of San Diego. Treatment at PLWTP consists of the following unit processes: bar screening, grit removal, coagulation/flocculation/sedimentation, and effluent screening. Chemical additions include ferric chloride $(27 \mathrm{mg} / \mathrm{L}$, average dose) just upstream of the coagulation process and a longchain, high-molecular-weight anionic polymer $(0.15 \mathrm{mg} / \mathrm{L}$, average dose), which is added during the coagulation process to assist in sedimentation. Source water for this study was taken from two locations in the PLWTP process-(1) upstream of the coagulation process (i.e., raw wastewater), and (2) after sedimentation (i.e., advanced primary effluent). Figure 1 shows a schematic of the PLWTP and indicates the location of the MBR pilot feed sources used during the study.

Table 1 presents feed wastewater characteristics measured from both feed wastewater sources during the course of this study. As shown, the organic (5-day biochemical oxygen demand $\left[\mathrm{BOD}_{5}\right] /$ chemical oxygen demand [COD]) and particulate (total suspended solids [TSS]/volatile suspended solids [VSS]) contaminants measured in the raw wastewater were consistent and typical of medium- strength municipal wastewater. As expected, the advanced primary treatment process was effective at removing these parameters, as indicated by the lower values observed in the advanced primary effluent. The ammonia concentrations in both wastewater sources were similar (approximately $26 \mathrm{mg} / \mathrm{L}-\mathrm{N}$ ) and typical of municipal wastewater.

Membrane Bioreactor Pilot Systems. Four submerged MBR pilot systems were used during this study. System suppliers included US Filter/Jet Tech, Enviroquip/Kubota, Zenon, and Ionics/ Mitsubishi. Table 2 presents membrane specifications for each system tested. As indicated, all systems contained hollow fiber membranes, with the exception of the Kubota MBR system, which uses flat sheet membranes. In addition, based on nominal pore size, three of the membranes (US Filter, Kubota, and Mitsubishi) can be classified as microfiltration, while Zenon membranes are ultrafiltration. Pilot capacities, during operation at average operating flux, ranged from 15 to $67 \mathrm{~L} / \mathrm{min}$. Lastly, the membrane modules/ cassettes used in each pilot were equivalent in size, configuration, and material as those used in full-scale applications. A complete description of each individual pilot system is provided below.

Kubota Membrane Bioreactor Pilot System. This system consisted of a rotary brush prescreen $(3.0 \mathrm{~mm})$, equalization storage tank, and a process tank. The process tank was partitioned into three zones-denitrification/anoxic $\left(6.4 \mathrm{~m}^{3}\right)$, preaeration $\left(2.4 \mathrm{~m}^{3}\right)$, and nitrification/aerobic $\left(10.1 \mathrm{~m}^{3}\right)$, for a total volume of $18.9 \mathrm{~m}^{3}$. As shown in Figure 2, two membrane cassettes were submerged in the aerobic tank in a double-deck configuration. Each cassette contained 100 individual type 510 flat sheet membranes, for a total membrane area of $160 \mathrm{~m}^{2}$. Feed wastewater entered the anoxic tank, where it was then pumped to the preaeration zone, where it underwent fine-bubble aeration. Next, the mixed liquor suspended

Table 1-Feed water quality analysis results.

Average values \pm standard deviation

\begin{tabular}{|c|c|c|c|}
\hline \multirow{2}{*}{ Parameter } & \multirow[b]{2}{*}{ Units } & \\
\hline & & (Raw wastewater) & (Advanced primary effluent) \\
\hline Ammonia-nitrogen & $\mathrm{mg} / \mathrm{L}$ & $26.7 \pm 2.03$ & $26.1 \pm 1.7$ \\
\hline Nitrate/nitrite-nitrogen & $\mathrm{mg} / \mathrm{L}$ & $0.70 \pm 0.42$ & $0.91 \pm 0.30$ \\
\hline Nitrite-nitrogen & $\mathrm{mg} / \mathrm{L}$ & $0.009 \pm 0.011$ & $0.020 \pm 0.034$ \\
\hline TSS & $\mathrm{mg} / \mathrm{L}$ & $249.3 \pm 52.7$ & $39.4 \pm 14.3$ \\
\hline VSS & $\mathrm{mg} / \mathrm{L}$ & $190.8 \pm 44.7$ & $28.0 \pm 4.3$ \\
\hline Total Kjeldahl nitrogen & $\mathrm{mg} / \mathrm{L}$ & $45.4 \pm 9.58$ & $26.8 \pm 10.5$ \\
\hline Orthophosphate-phosphorus & $\mathrm{mg} / \mathrm{L}$ & $0.60 \pm 0.40$ & $0.78 \pm 0.50$ \\
\hline $\mathrm{BOD}_{5}$ & $\mathrm{mg} / \mathrm{L}$ & $200 \pm 52$ & $106 \pm 25$ \\
\hline COD & $\mathrm{mg} / \mathrm{L}$ & $484 \pm 141$ & $224 \pm 40$ \\
\hline TOC & $\mathrm{mg} / \mathrm{L}$ & $39 \pm 10$ & $44 \pm 4$ \\
\hline
\end{tabular}


Table 2-Specifications of MBR membranes.

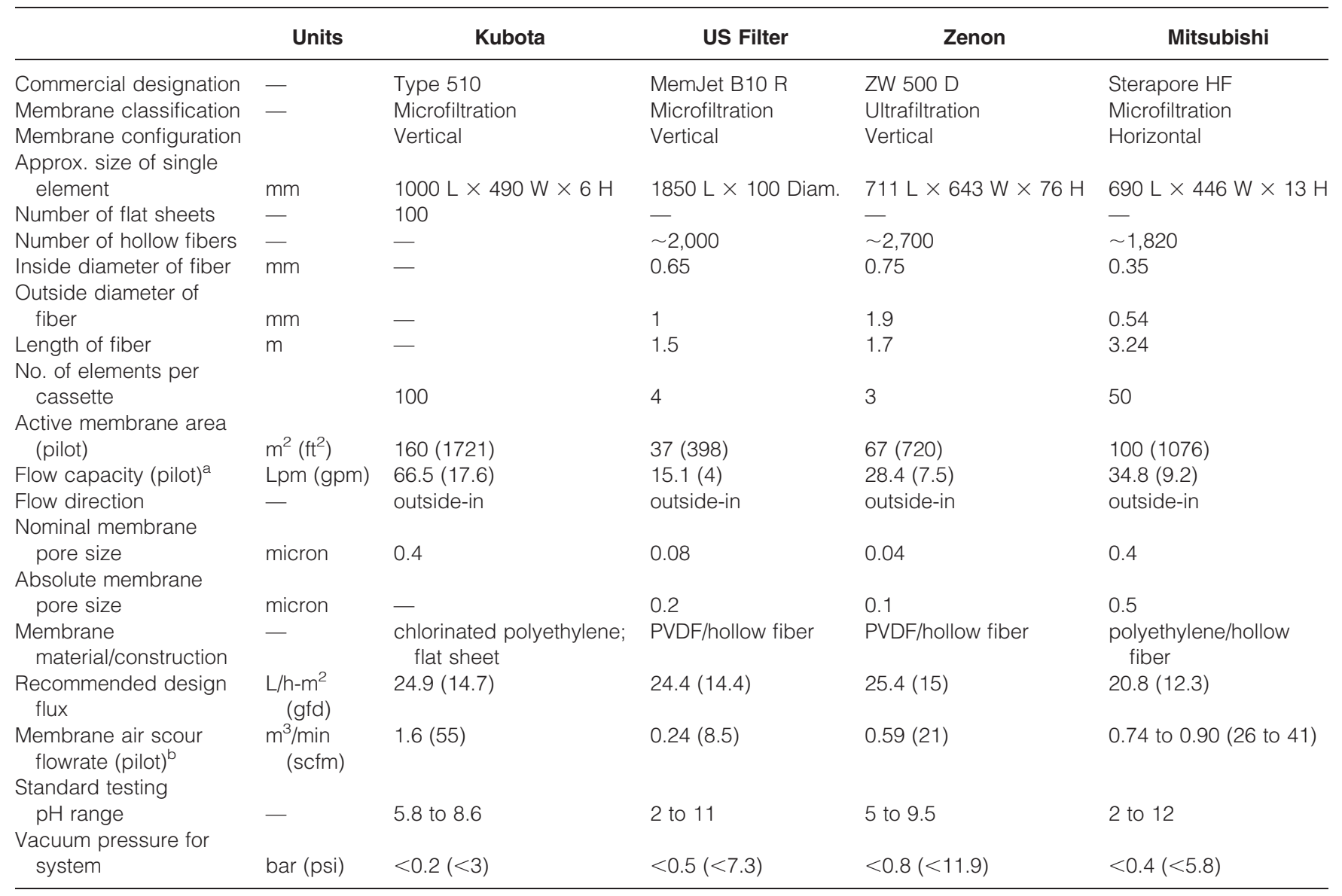

a Pilot operating at design flux.

${ }^{\mathrm{b}}$ Coarse bubble air only, does not include biological process air.

solids (MLSS) flowed by gravity to the aerobic tank, where coarse air bubbles provided membrane scouring. Lastly, MLSS was recycled from the aerobic tank to anoxic tank at approximately 4 times the permeate rate, to enable denitrification. At set intervals (9 minutes), permeate flow ceased, allowing the membranes to relax (1 minute) as a preventive measure to mitigate membrane fouling.

The purpose of the preaeration zone was to allow the optional use of the SymBio process. This process involves measuring nicotinamide adenine dinucleotide (NADH) to determine the change in biological oxygen demand to achieve simultaneous nitrification/ denitrification. Details of this process are provided elsewhere (Livingston, 2003). Because the aerobic and anoxic zones of the Kubota MBR pilot were adequate to achieve the desired nitrogen removal of this study, the SymBio process was not implemented.

US Filter Membrane Bioreactor Pilot System. A schematic of the US Filter MBR pilot system is provided in Figure 3. As shown, this pilot system included the following main components: rotary drum prescreen (wedge wire with 1.0-mm openings), aerobic tank $\left(9.8 \mathrm{~m}^{3}\right)$, membrane tank $\left(0.3 \mathrm{~m}^{3}\right)$, and permeate storage tank $\left(0.4 \mathrm{~m}^{3}\right)$. During operation, air and MLSS were continuously injected to the bottom of the membrane tank, to scrub and shake the membrane fibers. During filtration, a slight vacuum pressure was applied to the inside of the membrane fibers, to filter water from the outside in.
The MLSS, which was not filtered, overflowed the membrane tank at a rate of 4 to 6 times the permeate flowrate. The membrane tank contained four membrane modules containing hollow fiber membranes, with 0.2-micron pores, for a total membrane area of $37 \mathrm{~m}^{2}$. Per the manufacturer's recommendation, permeate water was frequently backwashed (12-minute intervals) from the inside to the outside of the membrane fibers, to prevent membrane fouling.

Zenon Membrane Bioreactor Pilot System. This system was comprised of a Roto-Sieve 0.8-mm perforated rotary drum screen (provided by Waste Tech Inc., Libertyville, Illinois), ZenoGem membrane unit $\left(0.8 \mathrm{~m}^{3}\right)$, and an aerobic tank $\left(10 \mathrm{~m}^{3}\right)$. As shown in Figure 4, feed wastewater entered the aerobic tank, where finebubble aeration provided adequate dissolved oxygen for biological oxidation. The MLSS was recirculated from the aerobic tank to the ZenoGem unit. One ZW 500d membrane cassette, containing three membrane elements, for a total area of $69 \mathrm{~m}^{2}$, was submerged in the ZenoGem unit. During operation, coarse air was used to scour the membranes and was cycled on/off at 10-second intervals. The membranes were also relaxed at a set interval of 10 minutes throughout testing.

Mitsubishi Membrane Bioreactor System. This pilot system included a prescreen, aerobic tank and permeate storage tank. As shown in Figure 5, two membrane cassettes containing hollow fiber membranes ( 0.5 nominal micron pore size) were submerged in the 


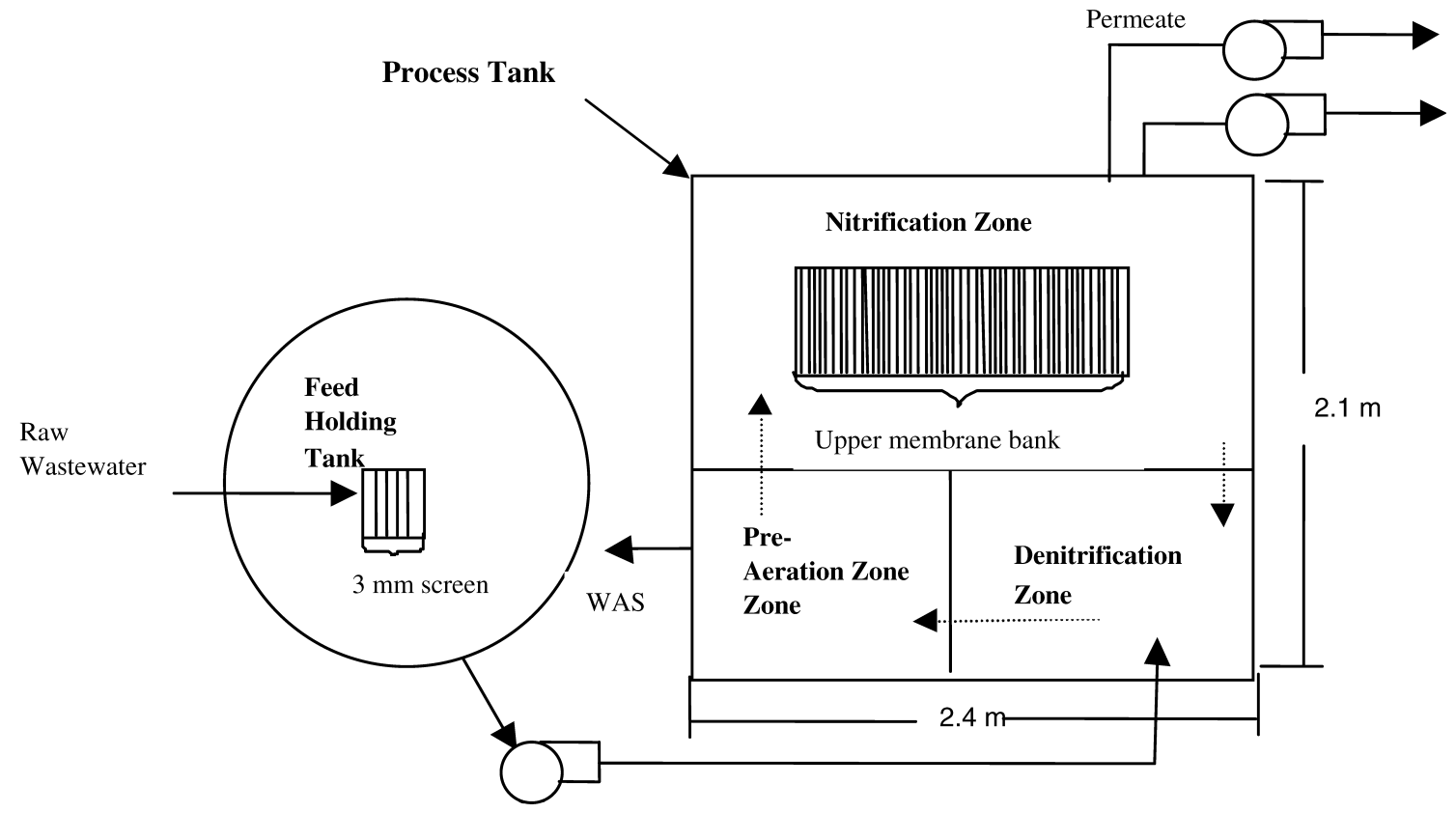

Figure 2-Kubota MBR pilot system schematic (plan view) (WAS = waste activated sludge).

aerobic tank, which had a total volume of $6 \mathrm{~m}^{3}$. Air diffusers, located in the bottom of the aerobic tank, continuously provided coarse air, to agitate the membranes and aerate the biomass. To supply additional oxygen for the increasing oxygen demands during more aggressive conditions (i.e., low HRT), the tank was retrofitted with fine-bubble diffusers. Each membrane bank consisted of 50, 1- $\mathrm{m}^{2}$ Mitsubishi Sterapore hollow fiber microfiltration membranes (Mitsubishi, Tokyo, Japan), for a total membrane area of $100 \mathrm{~m}^{2}$. The hollow fibers were arranged horizontally and attached at both ends to permeate lines. The membranes were relaxed at a set interval of 12 minutes, to prevent membrane fouling.

Pilot Operation. Each MBR pilot system underwent an initial startup period, which began by first seeding the biological process tanks with MLSS. The MLSS used to seed all MBR systems was obtained from a nearby full-scale secondary wastewater treatment plant. Next, the systems were supplied with feed wastewater and operated under constant flux conditions, to achieve a target MLSS level. The specific target MLSS concentrations for systems using

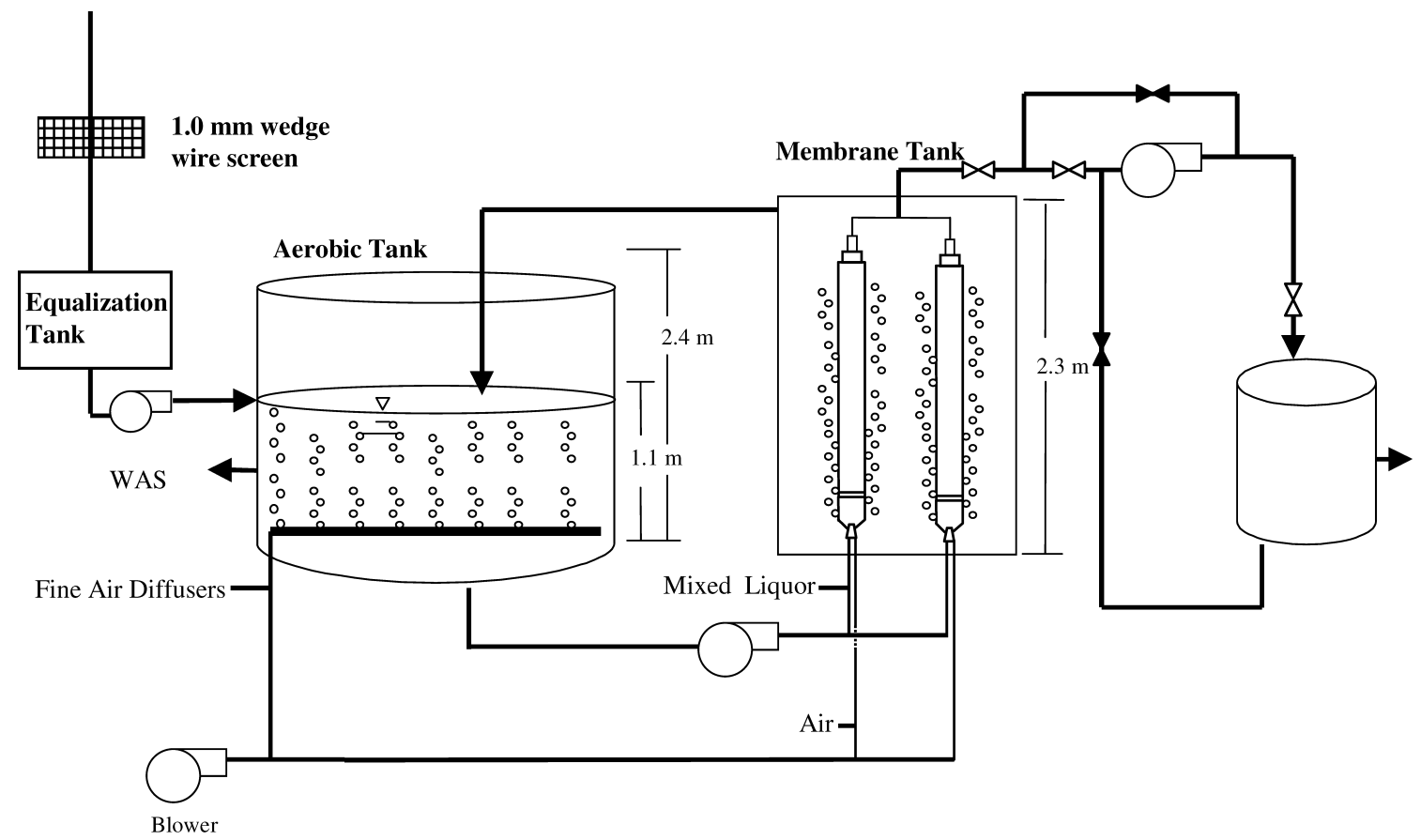

Figure 3-US Filter MBR pilot system schematic (WAS = waste activated sludge). 


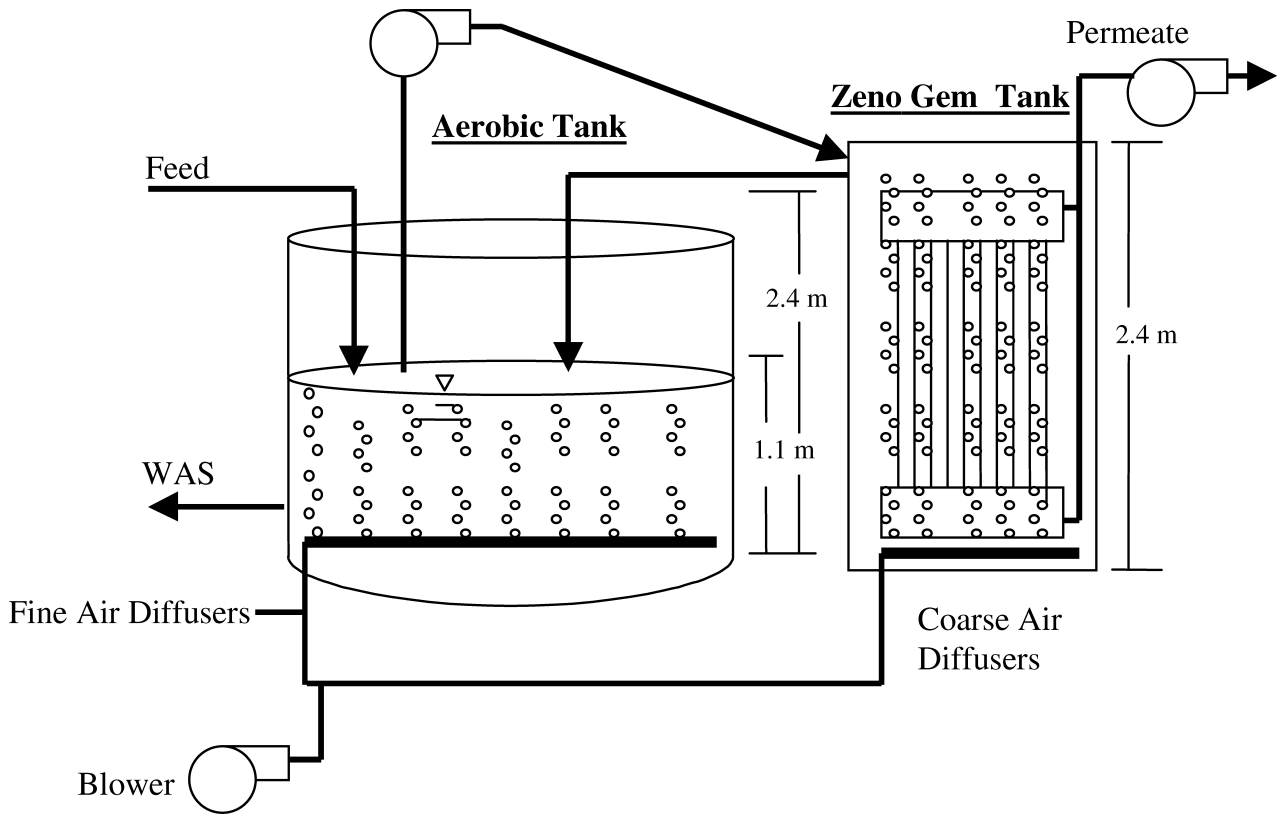

Figure 4-Zenon MBR pilot system schematic (WAS = waste activated sludge).

hollow fiber membranes were as follows: US Filter 9 to $12 \mathrm{~g} / \mathrm{L}$, Mitsubishi 10 to $12 \mathrm{~g} / \mathrm{L}$, Zenon 10 to $12 \mathrm{~g} / \mathrm{L}$, while the Kubota flat sheet membrane system ranged from 12 to $14 \mathrm{~g} / \mathrm{L}$. These values were established by consulting the individual manufacturers.

Once the target MLSS was achieved, it was maintained by implementing a mixed liquor wasting routine, which was performed on a daily basis. The time period for each wasting event ranged from 30 to 60 minutes and was dependent on the overall reactor volume, desired MLSS concentration, and wasting rate achieved by gravity or pumping waste sludge from each individual pilot system. Based on the target MLSS values, influent water quality characteristics, and reactor volumes, the SRT of the MBR pilot systems ranged from 11 to 40 days.

During operation on raw wastewater, feed wastewater was pumped from the grit chamber of PLWTP to the individual MBR systems using a centrifugal pump. When operating on advanced

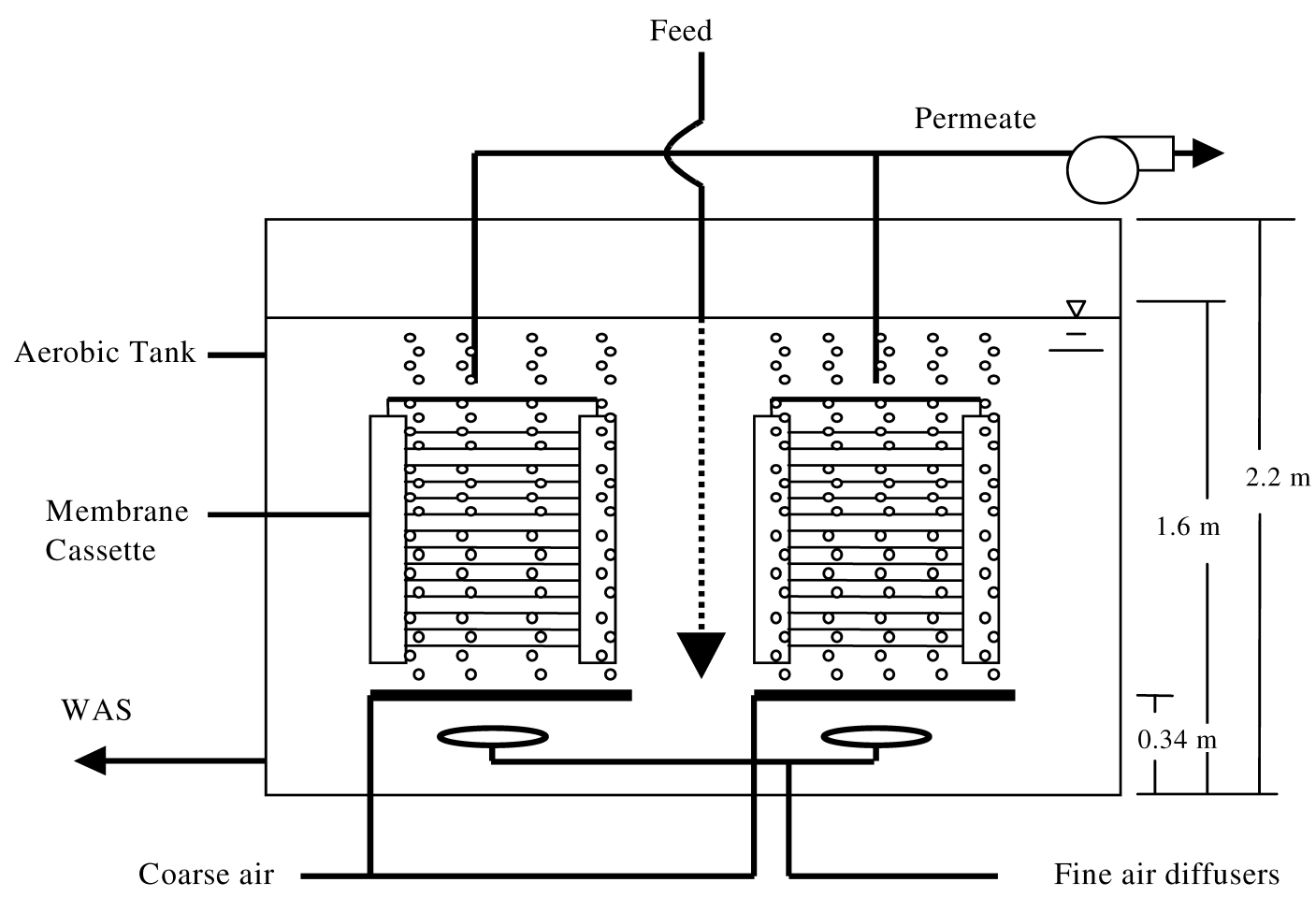

Figure 5-Mitsubishi MBR pilot system schematic (WAS = waste activated sludge). 
Table 3-Water quality analysis information.

\begin{tabular}{|c|c|c|c|}
\hline Category & Parameters & $\begin{array}{l}\text { Measurement } \\
\text { frequency }\end{array}$ & Method \\
\hline \multirow[t]{2}{*}{ Biological monitoring } & $\begin{array}{l}\text { Temperature, } \mathrm{pH}, \\
\text { dissolved oxygen }\end{array}$ & Daily & On-site \\
\hline & TSS/VSS & Daily & \\
\hline Particulates & Turbidity & Daily & SM 2130 B (APHA et al., 1998) \\
\hline Organics & $\mathrm{BOD}_{5}$ & Weekly & SM 5210 (APHA et al., 1998) \\
\hline \multirow[t]{2}{*}{ Microbial } & Total/fecal coliform & Weekly & SM 9221 E/B (APHA et al., 1998) \\
\hline & Coliphage & Weekly & SM 9224 F (APHA et al., 1998) \\
\hline \multirow{4}{*}{ Nutrients } & Ammonia & Weekly & SM 4500 B,E (APHA et al., 1998) \\
\hline & Nitrate/nitrite & Weekly & Hach 8171 (Hach, 1996) \\
\hline & Nitrite & Weekly & Hach 8507 (Hach, 1996) \\
\hline & Orthophosphate & Weekly & Hach 8048 (Hach, 1996) \\
\hline
\end{tabular}

primary effluent, feed wastewater was conveyed via a 5-cm pressurized line, which was tied into an existing $40-\mathrm{cm}$ pipe used at PLWTP for ocean discharge of treated effluent. Before reaching the MBR systems, all feed wastewater underwent fine screening. During the course of the study, three different types of screens were used. The specific screens tested were the Contra-Shear (New South Wales, Australia) Mini-milli model 450M screen containing 1.0-mm wedge wire slots; OR-TEC (Bedford, Ohio) rotary brush screen type C made with \#304 stainless steel and 3.1-mm perforations, and a Roto-Sieve (Kungälv, Sweden) model 6013-11 drum screen. A complete description and specifications for these screens is provided elsewhere (Adham and DeCarolis, 2004).

With the exception of the Kubota MBR, all systems were operated with nitrification only. The dissolved oxygen level in the aerobic tank of each system was measured daily, to ensure that adequate oxygen was available for aerobic biological oxidation and nitrification. In general, the membranes of each system were cleaned in accordance with the manufacturers protocol, when a significant decrease in specific flux (i.e., $>20 \%$ ) was observed or when a change in operating conditions (i.e., flux, HRT, and feed water) was intentionally made.

During the initial project period, the US Filter and Kubota MBR systems were operated concurrently, to assess the effect of feedwater quality on performance. Later, the US Filter MBR was operated at different flux rates, to assess the effect of flux on membrane fouling. In the last part of the study, Zenon and Mitsubishi MBR systems were operated concurrently, to assess their performance on advanced primary effluent. During this time, the Zenon MBR system was operated under extreme hydraulic and organic loading conditions, to assess membrane fouling. Though it was not possible to operate all four systems concurrently, historical data from the PLWTP shows that the influent wastewater quality (i.e., temperature, BOD/COD, and ammonia) does not vary significantly throughout the year.

Determination of Calculated Parameters. Several parameters, specific to the MBR process, were established and determined throughout the testing period. These parameters include membrane permeate flux, HRT, SRT, F/M ratio, and transmembrane pressure (TMP). The productivity of each MBR system was monitored by evaluating the decline in specific flux and increase in TMP or permeate vacuum pressure during operation at constant flux. To account for changes in viscosity caused by variations in feed water temperature, all specific values were corrected to $20^{\circ} \mathrm{C}$. The specific methods used to determine the aforementioned parameters are provided elsewhere (Adham and DeCarolis, 2004; Adham et al., 2000).

Water Quality Analysis. A complete water quality analysis was conducted during this study, to investigate the performance of the MBR systems to remove solid, organic, and microbial contaminants present in the feed water. Specific water quality parameters measured for each contaminant group included turbidity for solids; $\mathrm{BOD}_{5}$, TOC, and COD for organics; and total coliform, fecal coliform, and coliphage for microorganisms. In addition, various species of inorganic nitrogen (i.e., ammonia, nitrate, and nitrite) were measured in the feed and permeate of each MBR system, to assess the degree to which nitrification/denitrification was occurring. Furthermore, orthophosphate was measured in the feed and permeate of each system, to evaluate the occurrence of biological phosphorus removal.

In addition to water quality performance parameters, several general biological process parameters, including temperature, $\mathrm{pH}$, dissolved oxygen, and TSS/VSS, were monitored on a routine basis. Table 3 provides specific information related to the measurement of each parameter identified above, including location, frequency, and method. All laboratory water quality analysis was performed at one of the following locations: PLWTP, the City of San Diego Water Quality Laboratory, Calscience Environmental Laboratories (Garden Grove, California), or the City of San Diego Marine Micro Laboratory.

All water quality samples were collected as grab samples using sample containers provided from the corresponding laboratory. All samples were transported to the laboratory in a cooler and were processed within the allowable holding period. During sampling, sample ports were allowed to flush before samples were collected. All microbial samples were collected using aseptic techniques.

\section{Results and Discussion}

Effect of Feed Wastewater Quality on Membrane Bioreactor Performance. Figure 6 presents the average TMP and flux data of the Kubota MBR system during operation on raw wastewater and advanced primary effluent. As shown in the upper graph, a sharp increase in TMP was observed during the initial 788 hours (33 days) of operation following the startup period. During this time, the TMP (kilopascals) increased from 9.5 to 40 while operating at a constant flux of $25 \mathrm{lmh}$. The manufacturer was notified of this occurrence 


\section{Kubota MBR System}

- Average TMP $\bullet$ Aerobic Tank Temperature

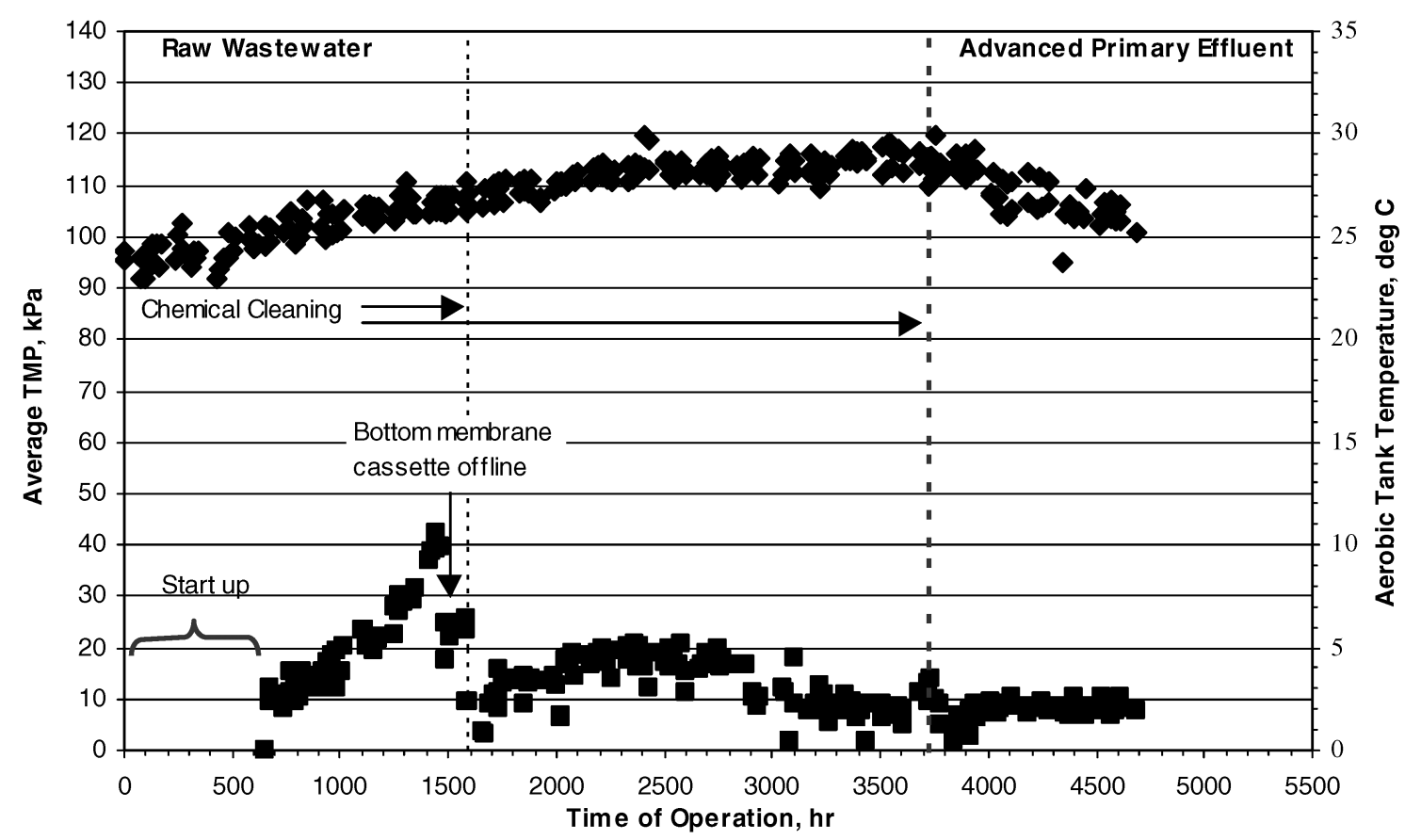

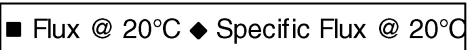

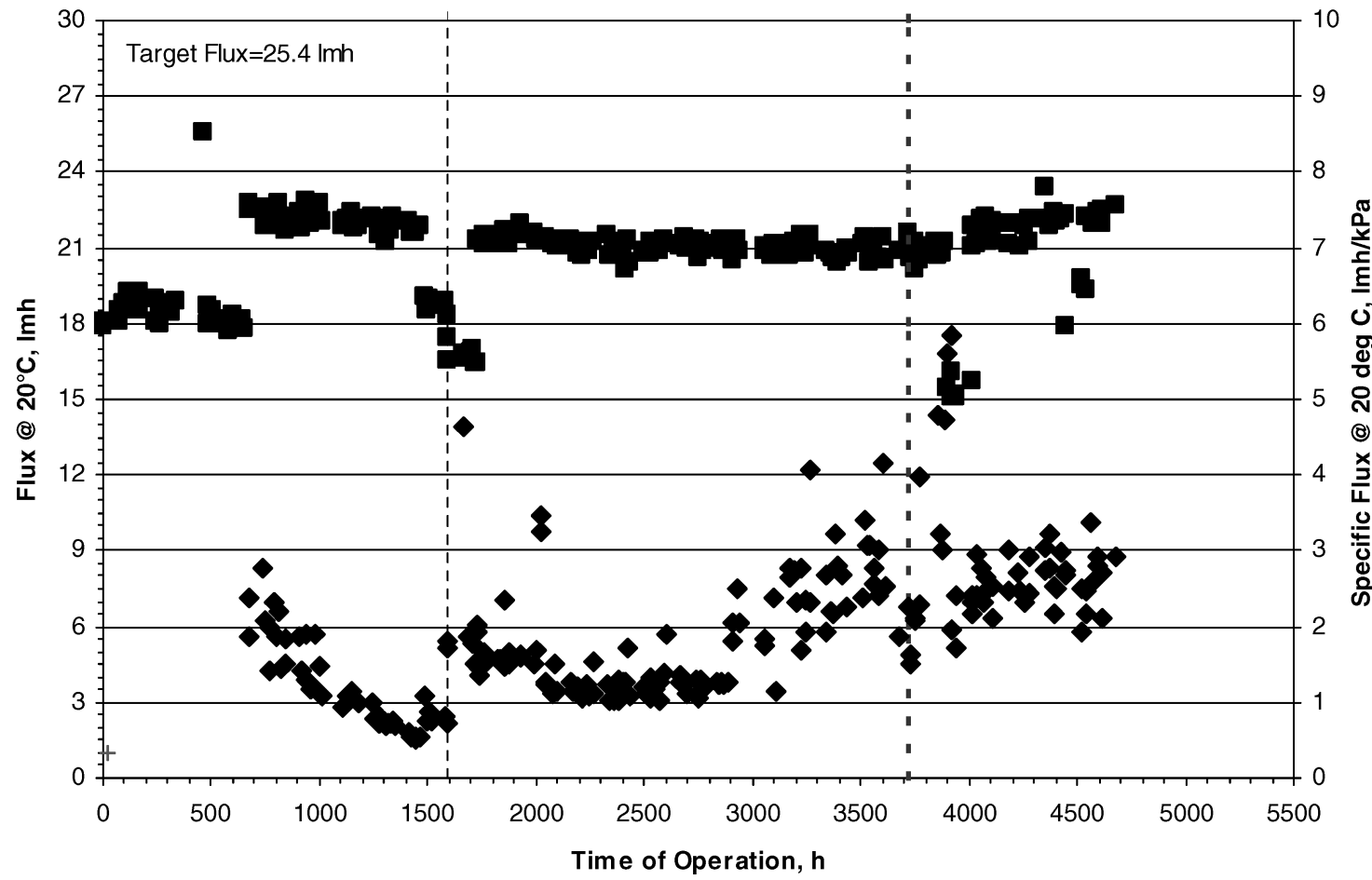

Figure 6-MBR performance under different feed wastewater conditions. 
and recommended that the bottom membrane bank be immediately taken offline to avoid damaging the membranes. As indicated, this reduced the TMP to $17 \mathrm{kPa}$. Shortly thereafter, the manufacturer sent field technicians to the pilot site to assess the cause of the fouling. During inspection, it was discovered that $1.9-\mathrm{cm}$ pipe was used for the permeate line. It is believed that this narrow piping may have resulted in flow restriction, which increased the pressure loss on the permeate side of the membranes. Accordingly, the permeate pipe was immediately replaced with $5.1-\mathrm{cm}$ pipe, which is standard design for full-scale Kubota MBR systems.

Following this pilot modification, the membrane cassettes were replaced, and the membranes were cleaned using chlorine and acid before bringing the system back in service. As shown, following the cleaning, the Kubota MBR operated on raw wastewater for over 2000 hours ( 83 days) at a flux of $25 \mathrm{lmh}$, with a TMP between 7 and $21 \mathrm{kPa}$, with little or no membrane fouling. Upon completing testing on raw wastewater, the membranes were cleaned again, and necessary piping connections were made, to allow for the system to be operated on advanced primary effluent. Next, the system was operated under similar operating conditions (i.e., flux and HRT) as tested on raw wastewater. As shown in Figure 6, the Kubota MBR system was operated on advanced primary effluent for 1800 hours (75 days) at $25 \mathrm{lmh}$, during which time, the TMP was between 7 and $14 \mathrm{kPa}$, with no fouling observed.

The above results indicate that residual coagulant and/or polymer existing in the advanced primary effluent at the time of this study did not adversely affect the MBR productivity. However, because the concentrations of residual coagulants/polymers were not measured during this study and can vary with respect to type and/or dose at different facilities, the authors would recommend those considering MBR conduct pilot testing on their specific wastewater to assess the potential effect of residual chemicals on membrane fouling before full-scale design.

Effect of Permeate Flux on Membrane Bioreactor Performance. Figure 7 presents TMP and flux data of the US Filter MBR system during operation at permeate flux ranging from 20 to $41 \mathrm{lmh}$. As indicated, the membranes were cleaned several times throughout the testing period following operation at a given flux. This allowed for a fair comparison of membrane performance at the various flux tested by starting each run with clean membranes. In addition, all operational runs shown were performed on raw wastewater, with a filtration cycle of 12 minutes, followed by a 45 -second relaxation and 15-second backwash period, and membrane air scour rate of $0.26 \mathrm{~m}^{3} / \mathrm{min}$.

As shown in Figure 7, the rate at which TMP increased with respect to time steadily increased as operating flux increased. This data suggests that operation at higher fluxes caused a significant increase in membrane fouling. The effect of flux on membrane fouling in MBR systems has been described by others (Chang et al., 2002; Gui et al., 2002; Le-Clech et al., 2006). To quantify the effect of flux on membrane fouling, data shown in Figure 7 collected were used to estimate the achievable runtimes between cleanings for flux values of 20, 25, and 31 to $41 \mathrm{lmh}$. As expected, the achievable runtime decreased steadily as flux increased, as follows: 69 days at $20 \mathrm{lmh}, 58$ days at $25 \mathrm{lmh}$, and 30 days during operation between 31 and $41 \mathrm{lmh}$. These runtimes were calculated by subtracting the specific flux at time of cleaning from the specific flux of clean membranes and dividing by the specific fouling rate (liters per square meter-hour per kilopascal per day) observed during operation at each flux. The time of cleaning was based on the maximum allowable TMP value, as recommended by the manufacturer.
Effect of Hydraulic Retention Time on Membrane Bioreactor Performance. Previous small-scale testing (Adham and Trussell, 2001) showed that MBR systems could successfully operate with an HRT of 2 hours (F/M approximately 0.18 day $^{-1}$ ). However, under these conditions, it was reported that the air supply system of the MBR was inadequate to maintain complete nitrification, making it necessary to provide pure oxygen. To gain more information regarding the effect of HRT on MBR performance, the project team worked closely with Zenon during the study, to allow their MBR pilot system to operate at short HRT values.

Operation at short HRTs is desirable, because it reduces the overall system footprint requirement for a given tank depth. However, a disadvantage is that, as HRT is reduced (holding MLSS constant), the organic loading rate to the system increases. A limited number of studies have shown membrane fouling to increase in MBR systems during operation at high organic loading rates (Cicek et al., 2001; Holler and Trosch, 2001; Trussell et al., 2006). Trussell et al. (2006) investigated membrane fouling at F/Ms ranging from 0.34 to $1.4 \mathrm{~g} \mathrm{COD} / \mathrm{g} \mathrm{VSS} \cdot \mathrm{d}$ and showed the highest level of membrane fouling to occur at F/Ms above $0.74 \mathrm{~g} \mathrm{COD} / \mathrm{g}$ VSS.d. The authors attributed this finding to observed increases in carbohydrate soluble microbial products concentrations in the MLSS at the higher organic loading conditions.

Figure 8 presents membrane performance data from the Zenon MBR system during operation at an HRT of 2 hours. The primary concern during operation at a low HRT was to maintain adequate dissolved oxygen for aerobic biological oxidation. Accordingly, the pilot system was designed to include a fine-bubble diffuser grid located in the aerobic tank to maintain a minimum dissolved oxygen level of $1.0 \mathrm{mg} / \mathrm{L}$. In addition, the pilot system was equipped with a variable frequency drive (VFD), to control the influent feed pump and programmable level control switch, which allowed the operating water level in the aerobic tank to be changed by the user interface of the control panel. During startup, the level in the aerobic tank was lowered gradually, to allow sufficient time to observe dissolved oxygen levels in the aerobic tank. Based on the reactor design and oxygen transfer limitations, it was necessary to increase the flux to $37 \mathrm{lmh}$, to reach the target 2-hour HRT.

As indicated in Figure 8, during startup, the VFD controlling the influent feed pump failed on several occasions, resulting in membrane fouling and system downtime. When the VFD malfunctioned at run hour 674, the feed water input to the system ceased. As filtration continued, the MLSS in the aerobic and membrane tank became concentrated, which eventually resulted in the permeate vacuum pressure to rise above the high alarm value, causing the system to shut down.

After replacing the faulty VFD, the membranes were cleaned (time of operation $=1350$ hours, which reduced the overall vacuum pressure from 52 to $16 \mathrm{kPa}$ ). The system was then placed in operation at a flux of $37 \mathrm{lmh}$ and HRT of 2 hours. As shown, the overall vacuum pressure remained near $17 \mathrm{kPa}$ for nearly 550 hours (23 days) of operation. However, between the hours of operation 1879 and 1900, the overall vacuum pressure increased sharply, from 19 to $66 \mathrm{kPa}$. As indicated in Figure 8, the rise in vacuum pressure occurred shortly after it was observed that nitrification was partially lost in the aerobic tank

The system was cleaned again at time of operation 1950 hours and placed back into operation. As indicated in Figure 8, at run hour 2350 , the mixed liquor was diluted because of a faulty wasting valve. The system was cleaned again after 2450 hours of operation, 


\section{US Filter MBR System}

- TMP $\diamond$ Membrane Tank Temperature

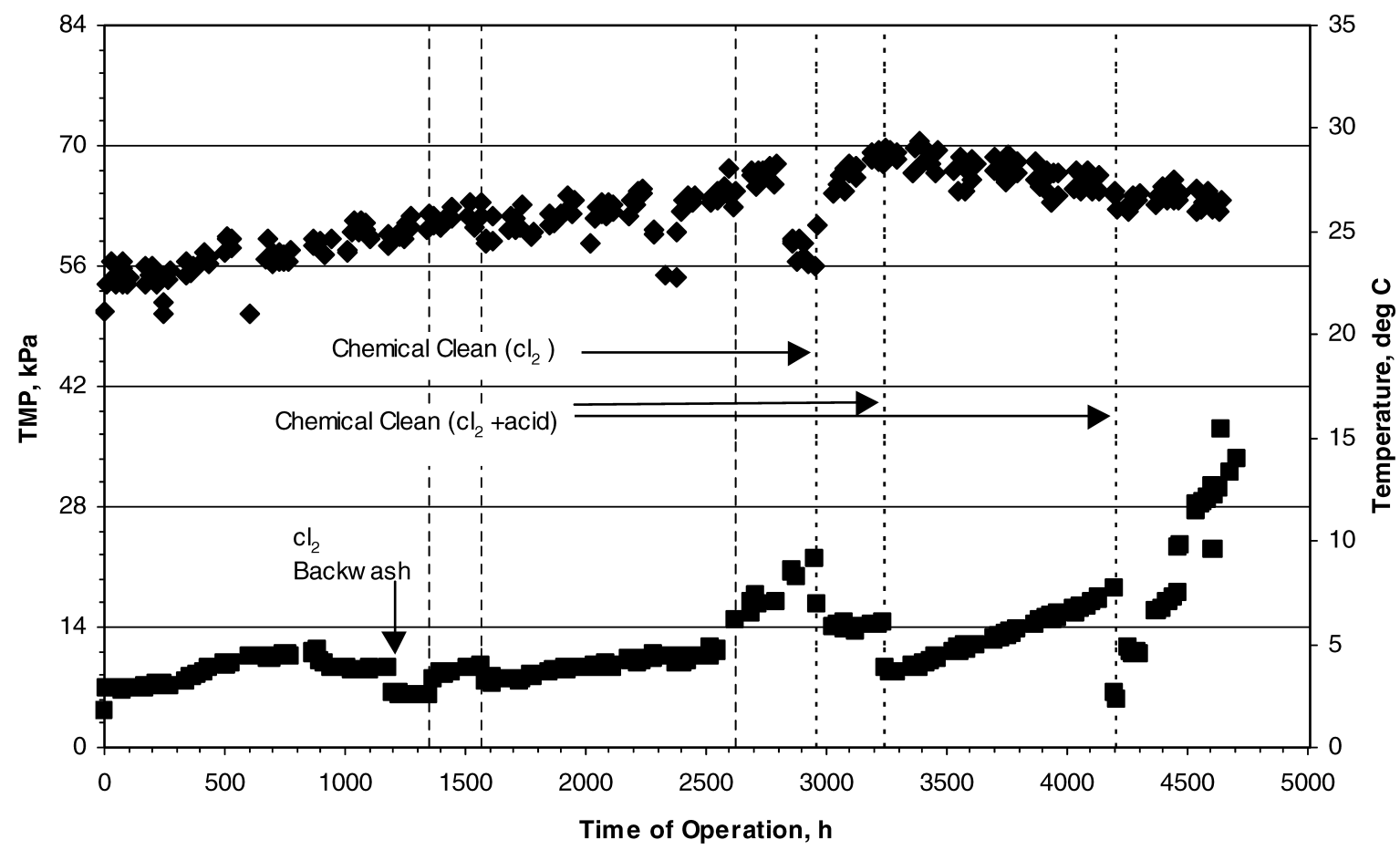

- Flux @ $20^{\circ} \mathrm{C} \bullet$ Specific Flux @ $20^{\circ} \mathrm{C}$

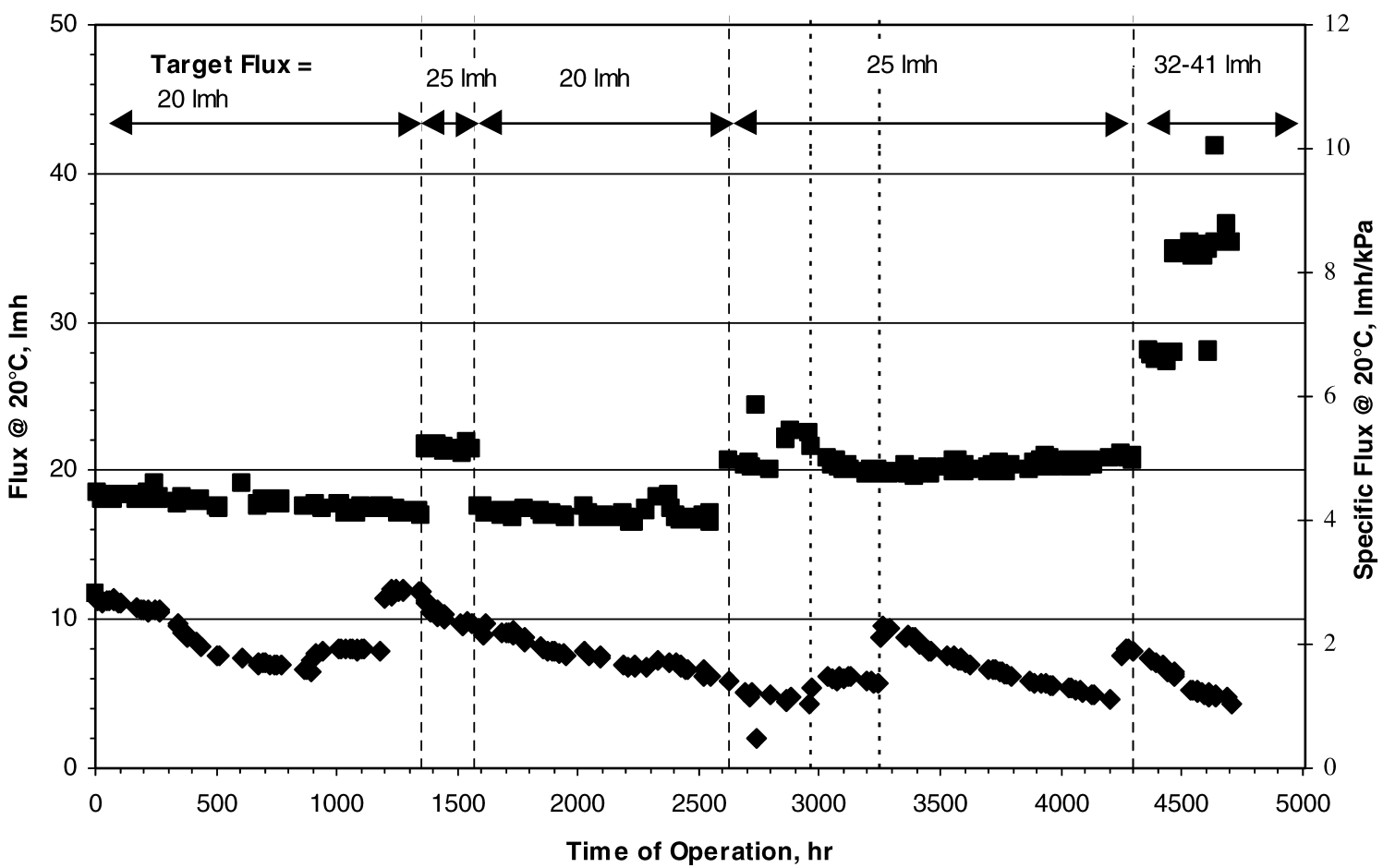

Figure 7-MBR performance at different permeate flux conditions. 

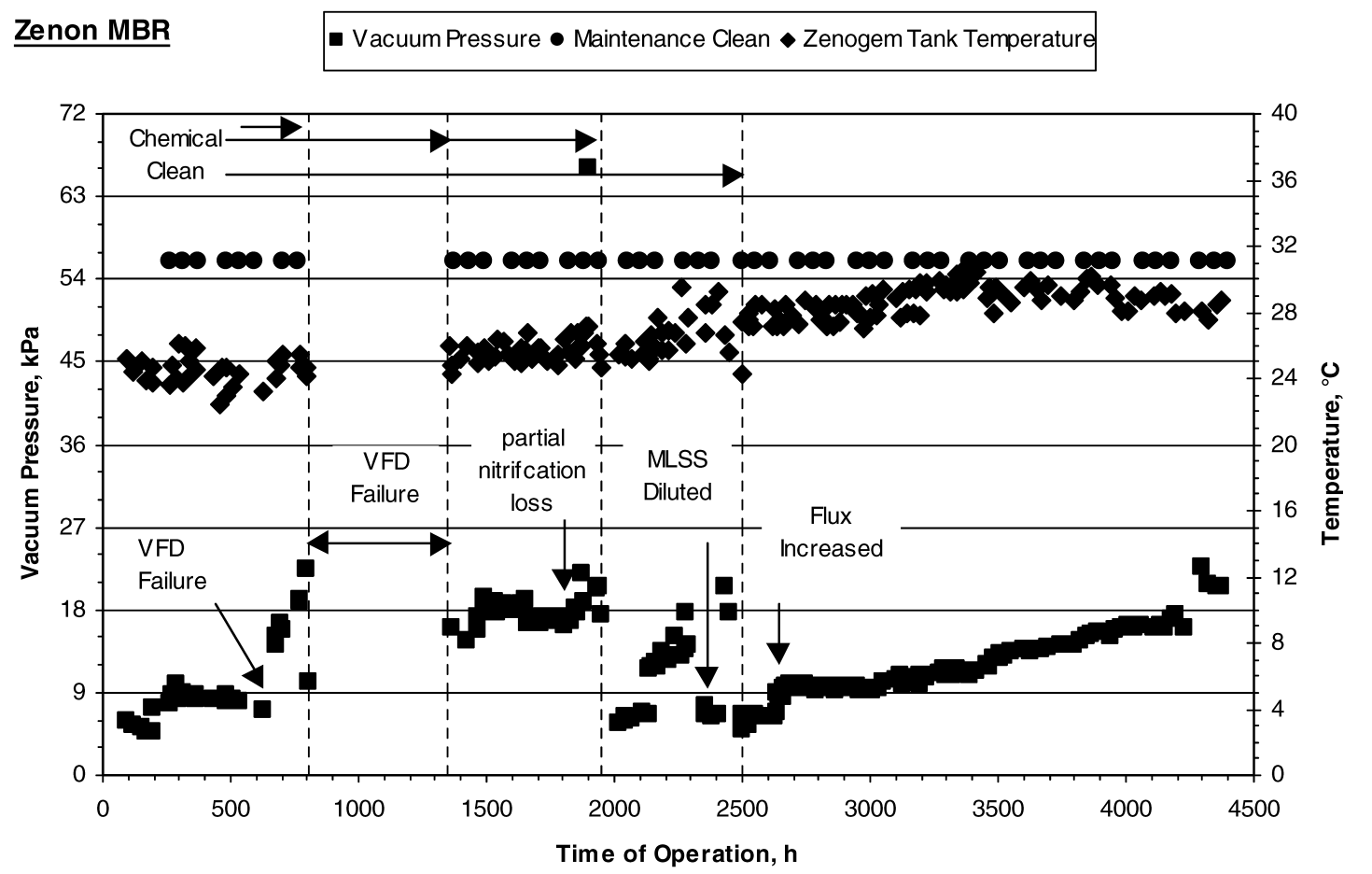

- Flux @ $20^{\circ} \mathrm{C} \diamond$ Specific Flux @ $20^{\circ} \mathrm{C}$

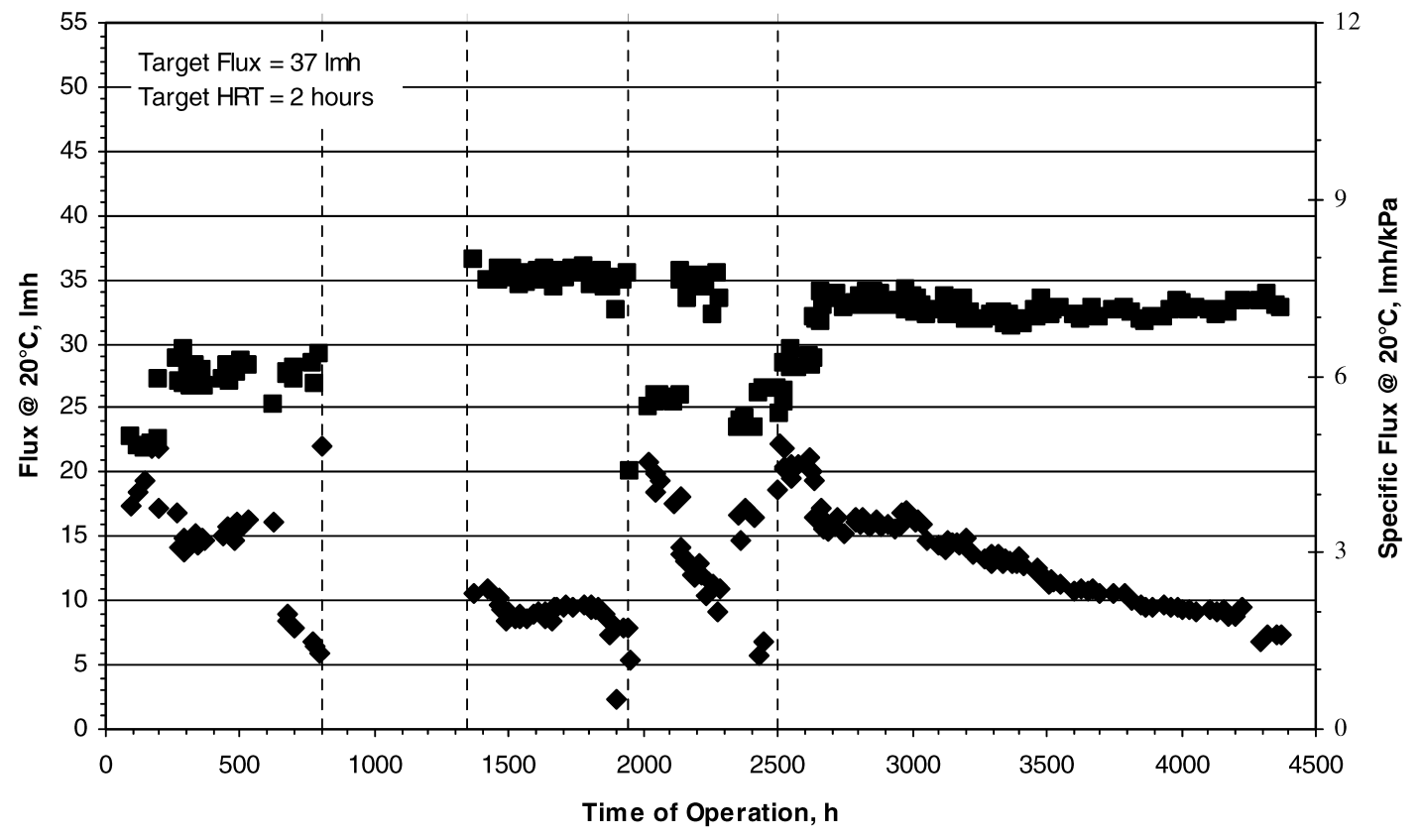

Figure 8-Membrane performance at short HRT conditions.

which reduced the overall vacuum pressure to $12 \mathrm{kPa}$. Post cleaning, the system was brought back online at a flux of $29 \mathrm{lmh}$. At 2639 hours of operation, the system was set back to the target operating conditions (i.e., flux $=37 \mathrm{lmh}$ and HRT $=2$ hours). Next, the ZW 500 d membrane was operated for over 1800 hours (75 days) at these conditions, during which time, the overall vacuum pressure only increased from 9 to $21 \mathrm{kPa}$. During this time, average values of $\mathrm{F} / \mathrm{M}, \mathrm{SRT}$, and MLSS were $0.33 \mathrm{gCOD} / \mathrm{gVSS} \cdot \mathrm{d}$, 19 days, and $10.8 \mathrm{~g} / \mathrm{L}$, respectively.

\section{Comparison of Membrane Bioreactor Systems}

Membrane Bioreactor Effluent Water Quality. A summary of the effluent water quality measured during the entire study for the four MBR systems tested is provided in Table 4. Overall, each 
Table 4-Summary of MBR effuent water quality.*

\begin{tabular}{|c|c|c|c|c|c|}
\hline $\begin{array}{l}\text { Water Quality } \\
\text { Parameter }\end{array}$ & Units & $\begin{array}{c}\text { US Filter } \\
\text { Avgerage } \pm \text { standard } \\
\text { deviation }\end{array}$ & $\begin{array}{c}\text { Kubota } \\
\text { Avgerage } \pm \text { standard } \\
\text { deviation }\end{array}$ & $\begin{array}{c}\text { Zenon } \\
\text { Avgerage } \pm \text { standard } \\
\text { deviation }\end{array}$ & $\begin{array}{c}\text { Mitsubishi } \\
\text { Avgerage } \pm \text { standard } \\
\text { deviation }\end{array}$ \\
\hline \multicolumn{6}{|l|}{ Particulate } \\
\hline Turbidity & NTU & $0.04 \pm 0.02$ & $0.08 \pm 0.02$ & $0.06 \pm 0.02$ & $0.07 \pm 0.01$ \\
\hline \multicolumn{6}{|l|}{ Nutrients } \\
\hline Ammonia-nitrogen & $\mathrm{mg}-\mathrm{N} / \mathrm{L}$ & $0.25 \pm 0.36$ & $0.60 \pm 1.5$ & $0.71 \pm 1.3$ & $3.1 \pm 5.3$ \\
\hline Nitrate/Nitrite-nitrogen & $\mathrm{mg}-\mathrm{N} / \mathrm{L}$ & $23.6 \pm 7.8$ & $2.95 \pm 1.23$ & $21.6 \pm 5.2$ & $15.2 \pm 7.7$ \\
\hline $\begin{array}{l}\text { Nitriate-nitrogen } \\
\text { Orthophosphate- }\end{array}$ & mg-N/L & $0.03 \pm 0.04$ & $0.02 \pm 0.01$ & $0.02 \pm 0.01$ & $0.5 \pm 1.5$ \\
\hline phosphorus & $\mathrm{mg}-\mathrm{N} / \mathrm{L}$ & $0.41 \pm 0.20$ & $0.15 \pm 0.13$ & $0.66 \pm 0.29$ & $0.67 \pm 0.35$ \\
\hline \multicolumn{6}{|l|}{ Organics } \\
\hline $\begin{array}{l}\mathrm{BOD}_{5} \\
\mathrm{COD} \\
\mathrm{TOC}\end{array}$ & $\begin{array}{l}\mathrm{mg} / \mathrm{L} \\
\mathrm{mg} / \mathrm{L} \\
\mathrm{mg} / \mathrm{L}\end{array}$ & $\begin{aligned} 2 & \pm 0.87 \\
20.5 & \pm 13.4 \\
5.8 & \pm 1.2\end{aligned}$ & $\begin{aligned} &<2 \\
& 18.4 \pm 9.6 \\
& 6.5 \pm 1.4\end{aligned}$ & $\begin{aligned}<2 \\
17.3 \pm 8.6 \\
6.8 \pm 1.1\end{aligned}$ & $\begin{aligned} &<2 \\
& 23.2 \pm 5.3 \\
& 6.9 \pm 1.1\end{aligned}$ \\
\hline \multicolumn{6}{|l|}{ Microbials } \\
\hline $\begin{array}{l}\text { Total Coliform } \\
\text { Fecal Coliform } \\
\text { Inherent Total } \\
\text { Coliphage }\end{array}$ & $\begin{array}{l}\text { MPN/100 mL } \\
\text { MPN/100 mL } \\
\text { PFU/100 mL }\end{array}$ & $\begin{array}{c}386 \pm 674 \\
50 \pm 72 \\
13 \pm 13\end{array}$ & $\begin{array}{c}13 \pm 69 \\
3 \pm 4 \\
10 \pm 24\end{array}$ & $\begin{array}{c}807 \pm 1314 \\
9 \pm 22 \\
1 \pm 1\end{array}$ & $\begin{array}{c}7 \pm 7 \\
2 \pm 0 \\
13 \pm 22\end{array}$ \\
\hline
\end{tabular}

* Number of samples varied with parameter and MBR system; $N=5(\min ) N=206(\max )$.

system produced effluent low in particulate (i.e., turbidity $<0.1$ NTU); organics (i.e., BOD $<2 \mathrm{mg} / \mathrm{L}, \mathrm{COD}<25 \mathrm{mg} / \mathrm{L}$, and TOC $<7 \mathrm{mg} / \mathrm{L}$ ); and microbial contaminants (i.e., total coliphage $<13$ $\mathrm{PFU} / 100 \mathrm{~mL})$. The ammonia concentrations measured in the effluent of all systems were also low (i.e., 0.25 to $3.1 \mathrm{mg}-\mathrm{N} / \mathrm{L}$ ) throughout the study, indicating that the systems achieved complete nitrification. As expected, the concentration of nitrate in the Kubota MBR effluent was much lower (average $=2.9 \mathrm{mg}-\mathrm{N} / \mathrm{L}$ ) compared with the other systems tested (average $=20 \mathrm{mg}-\mathrm{N} / \mathrm{L}$ ), because it was the only system that contained both aerobic and anoxic zones allowing for nitrification/denitrification. Such data demonstrates the ability of the MBR systems to produce water that meets Title 22 reclaimed water standards established for membrane processes by the California Department of Health Services (CDHS, 2005).

As shown in Table 4, the average concentration of total coliforms measured in the effluent of the Zenon (807 MPN/100 mL) and US Filter (386 MPN/100 mL) MBR systems were noticeably higher than that measured in the other MBR systems ( $\leq 13 \mathrm{MPN} / 100 \mathrm{~mL})$. After further testing, it was determined that the high counts in the Zenon system were attributed to contamination on the permeate side of the membranes. This was confirmed by disinfecting the permeate piping of the system midway through the testing period, after which total coliform counts were consistently less than 2 MPN/100 mL.

Further evaluation of the US Filter MBR system suggested that total coliform removal of this system may have been affected by backwashing. For example, Figure 9 shows that the total coliform counts measured in the US Filter MBR (which used backwashing) permeate were significantly higher than those measured in the permeate of the Mitsubishi system, which operated with relaxation. As shown, total coliform counts were highest (230 to 3000 MPN/ $100 \mathrm{~mL}$ ) in the US filter permeate during the initial 1500 hours of operation and then decreased to values between 2 and $240 \mathrm{MPN} /$ $100 \mathrm{~mL}$ thereafter. In comparison, the Mitsubishi MBR system produced total coliform counts $\leq 23 \mathrm{MPN} / 100 \mathrm{~mL}$ in all samples, with many below the detection limit of $2.2 \mathrm{MPN} / 100 \mathrm{~mL}$.

A possible explanation for the high total coliform count observed in the US Filter MBR permeate follows. During backwashing, the permeate piping (also used for backwashing) of the US filter MBR became contaminated from bacterial growth, which occurred in the permeate storage tank. In addition, during backwashing, the dynamic layer formed on the membrane surface was removed, reducing the sieving ability of the membranes. Lastly, the trend of decreasing permeate total coliform data observed from the US filter MBR compared with consistent low permeate values observed in Mitsubishi MBR system also may be the result of differences in the pore size distribution. That is, as the time of operation increased, larger pores in the distribution became plugged, resulting in enhanced filtration. After discussing these potential causes with US filter, they have now incorporated relaxation instead of backwashing to the design of their full-scale MBR systems.

Membrane Characteristics. The membranes of the four MBR systems tested were made of the following chemical polymers: polyvinylidene fluoride (US Filter/Zenon), polyethylene (Mitsubishi), and chlorinated polyethylene (Kubota). Though there were differences in the functional groups of the membrane polymers, data from this testing did not suggest that the membrane material affected MBR performance. Another distinguishing membrane characteristic, which varied among suppliers, was the nominal pore size and membrane classification. For instance, the US Filter, Kubota, and Mitsubishi MBR systems all contained microfiltration membranes (nominal pore sizes of $0.08,0.4$, and $0.4 \mu \mathrm{m}$, respectively), while the Zenon MBR system used ultrafiltration membranes, with a nominal pore size of $0.04 \mu \mathrm{m}$.

To date, it has been shown (CDHS, 1999, 2001) that ultrafiltration membranes can achieve 4 to $6 \log$ removal value (LRV) of MS2 phage, while microfiltration membranes are limited to 1 to 1.5 LRV. The ability of ultrafiltration to outperform microfiltration, with respect to virus removal, is the result of the difference in mem- 


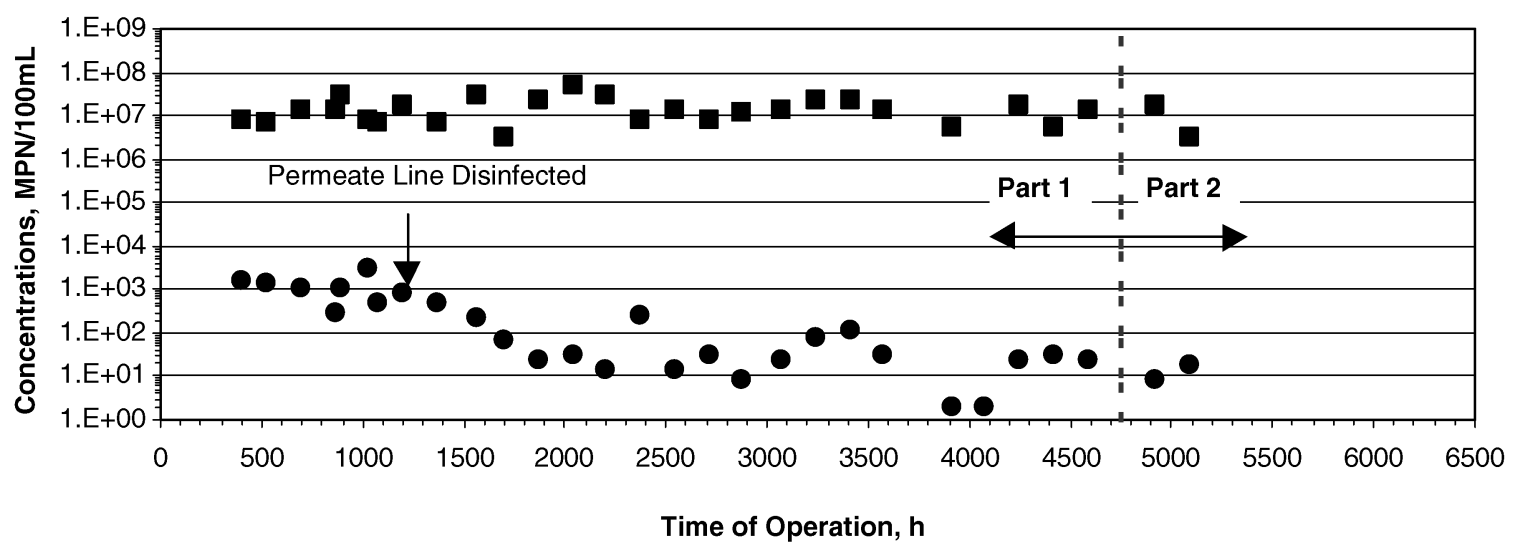

$\underline{\text { Mitsubishi MBR }}$

- Primary Effluent Total Coliforms $\bullet$ MBR Permeate Total Coliforms

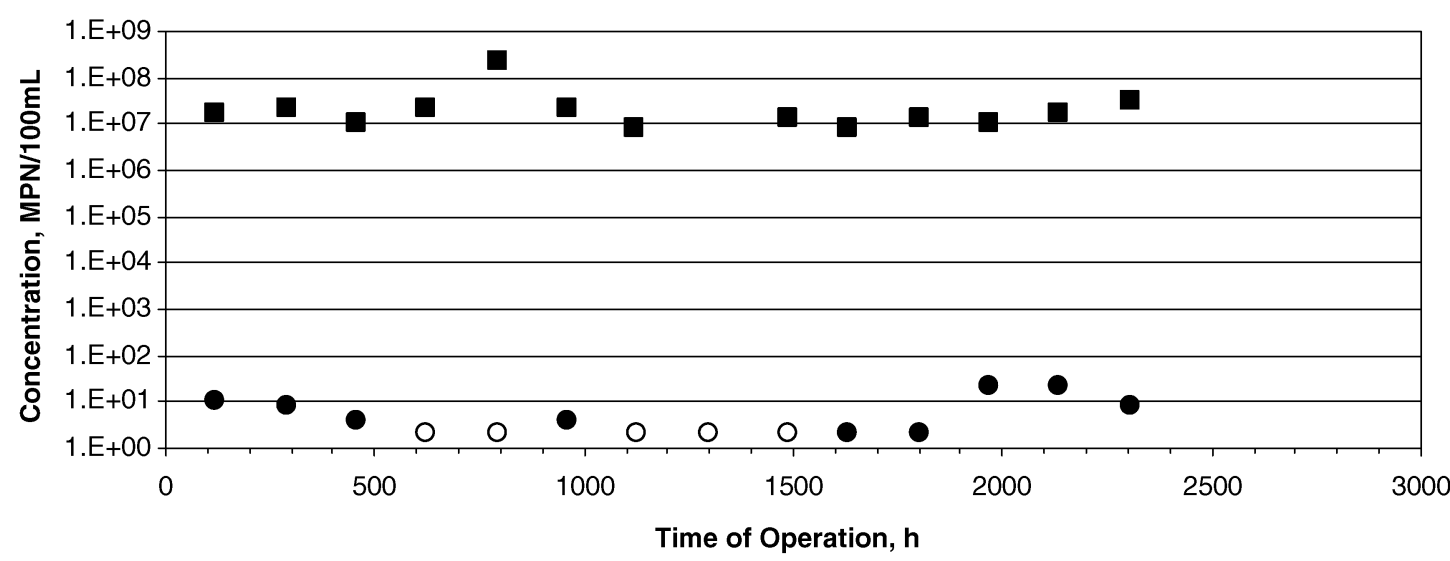

open symbols denote below detection

Figure 9-Total coliform removal: US Filter MBR system (top), and Mitsubishi MBR system (bottom).

brane pore size (typically 0.01 versus 0.1 micron, respectively). Because a virus is approximately 0.025 micron in size, exclusion by microfiltration is only achievable by filtration through a dynamic cake layer formed on the membrane surface.

To assess the effect of membrane pore size on virus removal in MBR systems, samples were collected from the feed wastewater and permeate of the Zenon (ultrafiltration) and Mitsubishi (microfiltration) MBR systems. As shown in Figure 10, the Zenon MBR achieved between 4.0 and 5.5 LRV removal of coliphage, with all permeate values at or below the detection limit of $1.0 \mathrm{PFU} / \mathrm{mL}$. Interestingly, the Mitsubishi MBR system also achieved high levels of coliphage removal (i.e., 3.0 to 5.0 LRV). A close look at the data collected from the Mitsubishi MBR system during the first 1100 hours of operation clearly shows a trend of decreased permeate coliphage with increasing time of operation. This would be expected for two reasons. First, the amount of total coliphage absorbed to the MLSS increases with increased solids concentration. Second, as the membranes become clogged, the pore size is decreased, which results in the removal of virus and other particles that could normally pass through the membrane pores.
Another important membrane characteristic, which also varies among suppliers, is the pore size distribution. For example, based on information obtained from the individual manufacturers during testing, the nominal and absolute pore sizes (microns) of the US Filter MemJet B10 R are 0.08 and 0.2 , respectively, while the Mitsubishi Sterapore hollow fiber membrane pore sizes are 0.4 and 0.5 , respectively. Membranes characterized with broad pore size distributions may have the potential to allow passage of microbial contaminants that are significantly larger than the nominal membrane pore size.

Prescreening. All MBR systems tested during this study required prescreening of influent wastewater before entering the biological process tanks. This was accomplished using a variety of different types of screening equipment, which were either equipped on the individual MBR systems or provided by commercial suppliers. The specific screens tested follow Contra-Shear Minimilli model 450M screen containing 1.0-mm wedge wire slots, ORTEC rotary brush screen type $\mathrm{C}$ containing $3.0-\mathrm{mm}$ perforations, and a Roto-Sieve model 6013-11 drum screen containing 0.8-mm circular perforations. 


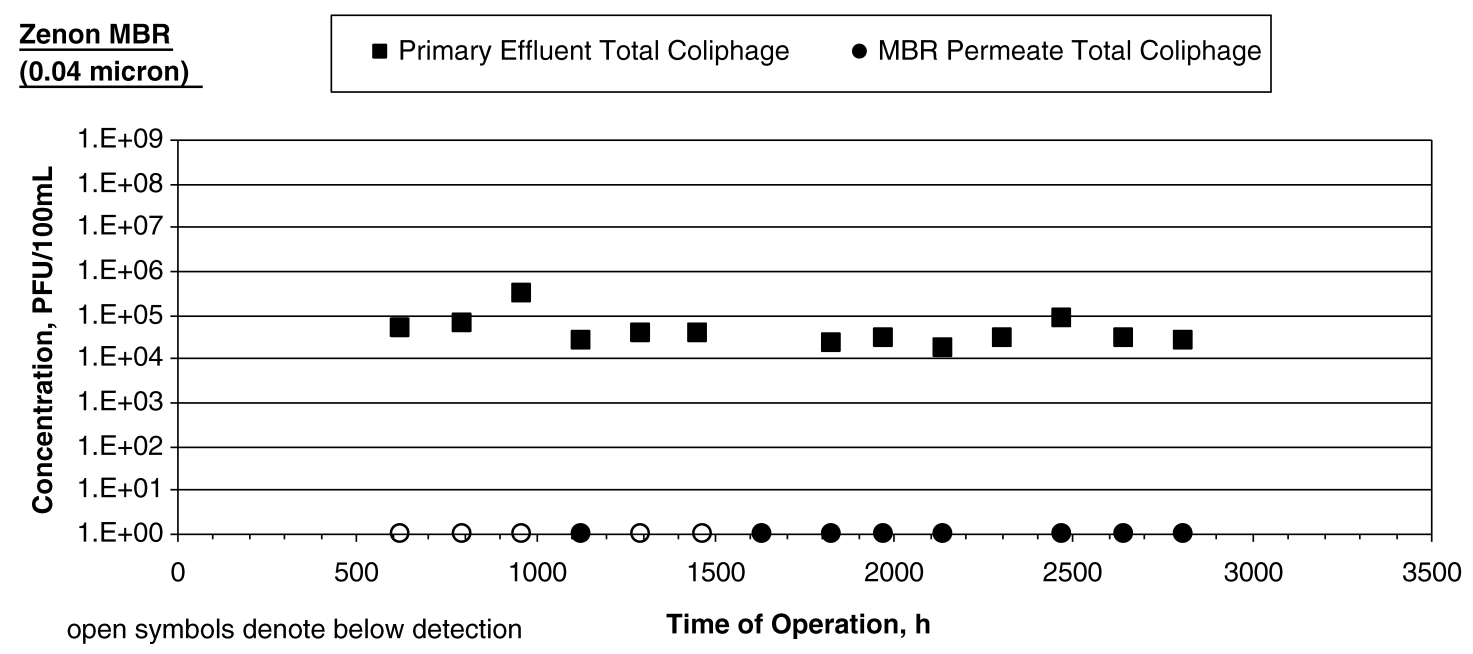

open symbols denote below detection

Time of Operation, $\mathrm{h}$

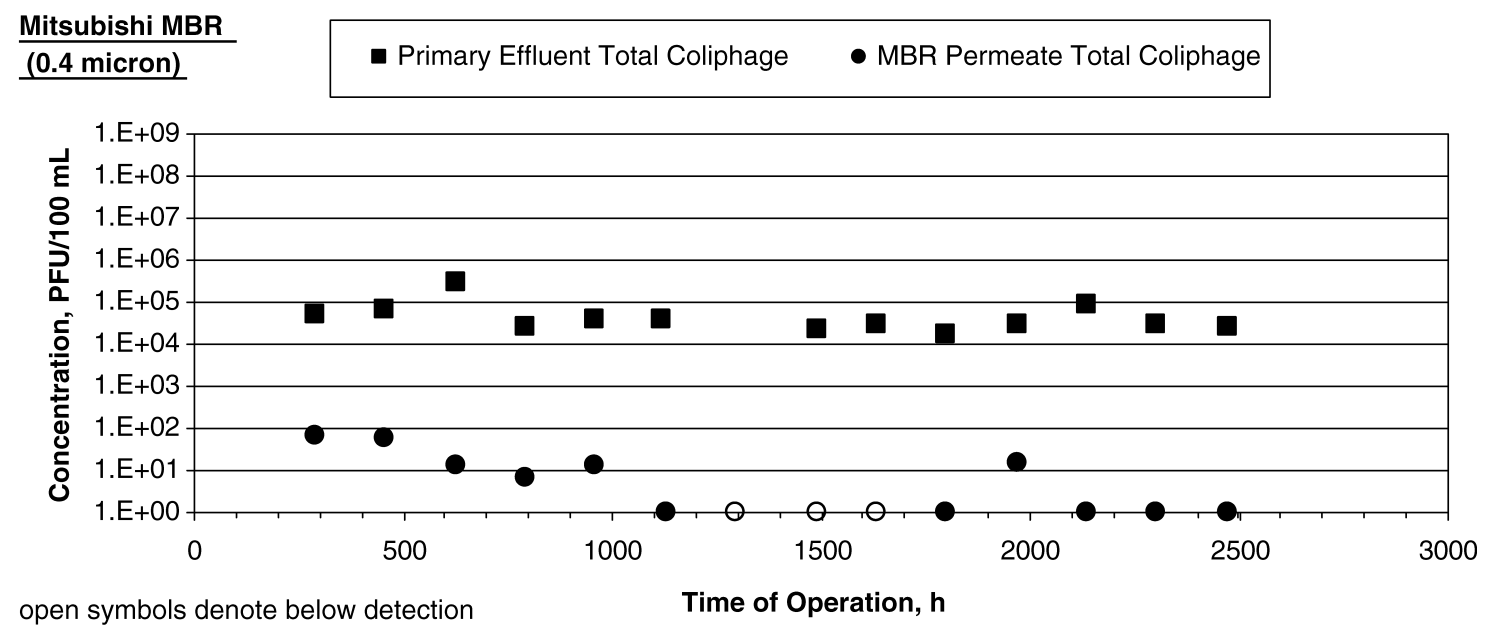

Figure 10-Total coliphage removal: Zenon MBR system (top), and Mitsubishi MBR system (bottom).

Throughout the study, differences were observed in the performance and maintenance requirements of the various screens tested. For example, the Contra-Shear drum screen, equipped on the US Filter MBR, allowed passage of hair and other fibrous material, which resulted in clogging of the piping leading to the membrane tank. On several occasions, clogging became so severe that the system shut down because of the low-flow alarm. The screen was also high-maintenance, requiring spraying of the surface daily to prevent clogging and disposal of large amount of debris too large to pass through the 1-mm slots.

The OR-TEC rotary brush screen, equipped on the Kubota MBR system, operated with low maintenance throughout the tested period. The screen was equipped with a brush assembly and scraper, which removed solids from the screen surface. In addition, the level of screening $(3 \mathrm{~mm})$ provided by the OR-TEC system appeared adequate for the Kubota MBR system throughout the testing period. It is expected that MBR systems that use flat sheet membrane configurations may require a lower degree of screening than those using hollow fibers, which are susceptible to becoming entwined with hair and other debris.
The Roto-Sieve (RS) drum screen, provided by Waste Tech Inc., also operated with relatively low maintenance throughout the test period. This was largely the result of the screen being equipped with a counter rotating roller brush and sprayer, which served to continuously clean the screen and prevented clogging of the perforated slots. Though the perforations of the Roto-Sieve were similar in size to the Contra Shear screen $(0.8 \mathrm{~mm}$ versus $1 \mathrm{~mm})$, the Roto-Sieve screen appeared to remove the majority of hair and long fibers present in the wastewater. This is attributed to the circular shape of the perforations contained on the Roto-Sieve, as opposed to the slotted perforations of the Contra Sheer screen.

Membrane Fouling Control. Several types of membrane fouling control methods were used during this study. These included frequent relaxation/backwashing, air scouring, periodic recovery cleans, and maintenance cleaning.

Relaxation versus Backwashing. Throughout the study, all MBR systems were operated with frequent membrane relaxation or backwashing (US Filter only) to mitigate fouling resulting from compaction of the cake layer formed on the membrane surface. During relaxation, filtration was temporarily ceased, while coarsebubble aeration was continued to provide membrane air scouring. 
The frequency and duration of relaxation differed among the three suppliers, but, in general, ranged from 9 to 12 minutes and 0.5 to 2 minutes, respectively. The US Filter MBR system backwashed every 12 minutes, which began by relaxing the membranes for 45 seconds, followed by a 15 -second backwash period. During backwashing, filtrate water was pumped from the inside to the outside of the membrane fiber.

The use of relaxation, as opposed to backwashing in MBR systems, offers several advantages. For instance, relaxation eliminates the need for additional permeate storage tanks, valves, and piping. In addition, backwashing requires the consumption of product water, which ultimately reduces the net productivity of the MBR system. Lastly, as reported by Adham and Gagliardo (1998), membrane integrity is another factor to consider in systems that use sequential backwashing. The authors explained that, during filtration, the applied vacuum pressure typically causes the solids to clog broken fibers. However, on systems that use backwashing, these seals can become broken over time, making it necessary to replace the compromised fiber(s).

Membrane Air Scouring. Each MBR system used coarsebubble aeration to reduce membrane fouling. The instantaneous membrane air flowrates (cubic meters per minute) per membrane area (square meters) varied among suppliers, as follows: Zenon = 0.009 , US Filter $=0.007$, Kubota $=0.010$, and Mitsubishi $=$ 0.012. All MBR systems operated with constant membrane air scour, except Zenon, which cycled on/off at 10-second intervals. This type of intermittent operation reduced the amount of air required for membrane air scouring by $50 \%$ and was equivalent to an instantaneous air flowrate of $0.0045 \mathrm{~m}^{3} / \mathrm{min} / \mathrm{m}^{2}$.

Recovery Cleaning. In general, recovery cleanings are performed on MBR systems when a significant loss of membrane permeability has occurred. Though the cleaning frequency can vary based on operation and water quality, for municipal wastewater treatment applications, it is typically recommended to perform this level of cleaning once or twice per year. The cleaning protocols from all four MBR suppliers specify the use of similar chemicals, including chlorine ( 2 to $3 \mathrm{~g} / \mathrm{L}$ ), followed by citric or oxalic acid (2\%). However, the cleaning procedures varied among suppliers. In general, the MBR systems were either cleaned in place (CIP) (Zenon and US Filter) or cleaned in-line (CIL) (Mitsubishi and Kubota). Details of the procedures used to clean the membranes of each MBR system during this study are provided elsewhere (Adham and DeCarolis, 2004).

During a CIP, the membranes were isolated from the MLSS, and chemicals were continuously circulated through the membranes before soaking. During CIL, the membranes were not isolated from the MLSS, and chemical was allowed to slowly flow by gravity from the inside to the outside of the membranes. This procedure introduced chemicals to direct contact with activated sludge.

Data from this study showed that both methods of cleaning were effective at restoring specific flux and TMP to values near those established at the onset of testing on new membranes. However, because of direct contact of cleaning chemicals with the mixed liquor and design characteristics of the pilot systems, various degrees of foaming occurred in the Kubota and Mitsubishi MBR systems during post cleaning operation. For the Kubota MBR system, which transferred MLSS from the anoxic to aerobic zone, foaming was mitigated within 1 or 2 days following a cleaning event with no added foam control. However in the case of Mitsubishi, which was only operated with an aerobic tank, foaming persisted for several weeks after cleaning. As a result, it was necessary to install and operate a sprayer system and add chemicals to the mixed liquor for foam control. For full-scale MBR applications (i.e., $>2000 \mathrm{~m}^{3} / \mathrm{d}$ ), most MBR systems, regardless of the selected manufacturer, would be designed to allow membrane cleanings to be performed in-place.

Maintenance Cleaning. Another fouling preventative measure on MBR systems is the use of maintenance cleanings. Unlike recovery cleanings, this type of cleaning is done on a more frequent basis, in an effort to continuously keep the membranes clean. For instance, during this study, the Zenon MBR system operated with maintenance cleanings, which were performed three times per week (2/week, $250 \mathrm{mg} / \mathrm{L}-\mathrm{NaOCl}, 1 /$ week, citric acid-2 \%). Each maintenance clean only lasted 10 minutes, during which time, the membranes were backwashed and relaxed at alternating 30-second intervals. Backwashing was conducted with permeate water, to which desired chemicals had been added. The use of backwashing during maintenance cleaning is only conducive for MBR systems using hollow fiber membranes, as they can withstand backpressure.

\section{Summary and Conclusions}

Four commercially available MBR systems were operated at the pilot-scale during a 16-month period, to investigate performance during the reclamation of municipal wastewater. During this time, MBR performance was evaluated under a variety of operating conditions, including two types of feed wastewater (raw and advanced primary effluent), HRTs ranging from 2 to 6 hours, and permeate flux ranging from 26 to $41 \mathrm{lmh}$. Operational and water quality data collected from the MBR systems were compared to gain insight to how differences among suppliers affected performance. Primary inferences from this study are summarized as follows:

- Data from this study showed that MBRs can successfully operate on advanced primary effluent produced from feed wastewater treated with coagulant $(27 \mathrm{mg} / \mathrm{L}$ ferric chloride) and organic polymer $(0.15 \mathrm{mg} / \mathrm{L})$. This is an important finding to the wastewater treatment community, as it increases the number of potential applications MBR can serve in the wastewater reclamation arena. Potential benefits of operating MBR systems on advanced primary effluent, as opposed to raw wastewater, include the following: reduction of process air requirements resulting from reduced solid/organic loading, less susceptibility to changes in water quality, lower prescreen maintenance requirements, and reduced footprint.

- Membrane fouling was observed to increase as operating flux increased. This is primarily attributed to an increase in the mass loading of solid, organic, and microbial contaminants. As a result of increased fouling, the calculated runtime between cleanings associated with the maximum allowable TMP of the membranes decreased with increasing flux, as follows: 69 days at $20 \mathrm{lmh}, 58$ days at $25 \mathrm{lmh}$, and 30 days during operation between 31 and $41 \mathrm{lmh}$.

- Data from this study showed that the MBR process can be optimized to operate under extreme operating conditions, including the following: 2-hour HRT, F/M of $0.33 \mathrm{~g} \mathrm{COD/g}$ VSS·d, and flux of $37 \mathrm{lmh}$. Under such conditions, the MBR operated for 75 days with minimal increase in TMP, and produced consistent water quality throughout the testing period, as follows: turbidity $\leq 0.1 \mathrm{NTU}, \mathrm{BOD}_{5} \leq 2 \mathrm{mg} / \mathrm{L}$, and ammonia $<0.6 \mathrm{mg} / \mathrm{L}$.

- Third-party evaluation of MBR systems is important to assess the effect of key variables (i.e., system configuration, membrane characteristics, membrane fouling control, prescre- 
ening, design flux, organic loading rate, and feed water quality) on performance.

\section{Credits}

The project team thanks the following groups for making this project possible:

- United States Bureau of Reclamation Technical Service Center Water Treatment Engineering and Research Group (Denver, Colorado) for funding Agreement No. 01FC810736.

- City of San Diego, California; William Pearce, Larry Wasserman, Steve Lagos, Neil Tran, and Dwight Smith, for support with pilot operation, data management, and project organization.

- Point Loma Satellite Laboratory (San Diego, California); Brent Bowman, Miles Slattery, Julie Webb, Enrique Blanco, Eric Becker, Patricia Ortega, Maricella Coronel and Greg Schlimne, for performing the majority of the water quality analysis required during the study.

- City of San Diego Marine Microbiology Laboratory (California); Laila Othman, Roxane Davis, Sonji Romero, George Alfonso, and Joseph Toctocan, for performing all microbial analysis conducted during this study.

- Point Loma Wastewater Treatment Plant (San Diego, California); Joe Cordova, Jim Linsday, K.C. Shankles, and Jim Golden, for their cooperation and support throughout the study. Staff of the electrical, maintenance, operations, engineering, and warehouse sections for their services during pilot testing.

- Participating vendors for supplying pilot equipment and technical support: US Filter Corporation/Jet Tech Products Group, Zenon Environmental, Inc., Ionics/ Mitsubishi Rayon Corporation, Enviroquip Inc./Kubota Corporation, and WasteTech, Inc./Roto-Sieve.

Submitted for publication January 23, 2006; revised manuscript submitted April 20, 2007; accepted for publication May 14, 2007.

The deadline to submit Discussions of this paper is March 15, 2008 .

\section{References}

Adham, S.; Gagliardo, P. (1998) Membrane Bioreactors for Water Repurification-Phase I, Desalination Research and Development Program Report No. 34, Project No. 1425-97-FC-81-30006J; Bureau of Reclamation: Denver, Colorado.

Adham, S.; Mirlo, R.; Gagliardo, P. (2000) Membrane Bioreactors for Water Reclamation-Phase II, Desalination Research and Development Program Report No. 60, Project No. 98-FC-81-0031; Bureau of Reclamation: Denver, Colorado.

Adham, S.; Trussell, S. (2001) Membrane Bioreactors: Feasibility and Use in Water Reclamation, Final Report Project \#98-CTS-5; Water Environment Research Foundation: Alexandria, Virginia.

Adham, S.; DeCarolis, J. (2004) Optimization of Various MBR Systems for Water Reclamation-Phase III, Desalination Research and Development Program Report No. 103, Project No. 01-FC-81-0736; Bureau of Reclamation: Denver, Colorado.
Aguilera Soriano, G.; Erb, M.; Garel, C.; Audic, J. M. (2003) A Comparative Pilot Scale Study of the Performance of Conventional Activated Sludge and Membrane Bioreactors under Limiting operating Conditions. Water Environ. Res., 75, 225-231.

American Public Health Association; American Water Works Association; Water Environment Federation (1998) Standard Methods for the Examination of Water and Wastewater, 20th ed.; American Public Health Association: Washington, D.C.

California Department of Health Services (1999) Zenon (ZeeWeed) Membrane, Final Report prepared by Montgomery Watson and the City of San Diego; California Department of Health Services: Sacramento, California.

California Department of Health Services (2001) US Filter PVdF Membrane, Final Report prepared by Montgomery Watson and the City of San Diego; California Department of Health Services: Sacramento, California.

California Department of Health Services (2005) Treatment Technology Report for Recycled Water; California Department of Health Services, State of California Division of Drinking Water and Environmental Management: Sacramento, California.

Chang, I.; Le Clech, P.; Jefferson, B.; Judd, S. (2002) Membrane Fouling in Membrane Bioreactors for Wastewater Treatment. ASCE J. Environ. Eng., 128 (11), 1018-1029.

Cicek, N.; Macomber, J.; Devel, J.; Suidan, M. T.; Audic, J.; Genestet, P. (2001) Effect of Solids Retention Time on the Performance and Biological Characteristics of a Membrane Bioreactor. Water Res., 30, 1771-1780.

Daigger, T. D.; Rittmann, B. E.; Adham, S. (2005) Are Membrane Bioreactors Ready for Widespread Application? Environ. Sci. Technol., 39 (18), 399a-406a.

Guendert, D.; Jordan E. (2004) Urban Reuse: Bringing Water Treatment Where It's Needed Most. J. Am. Water Works Assoc., 96 (6), 52-56.

Gui, P.; Xia Huang, P.; Chen, Y.; Qian, Y. (2002) Effect of Operational Parameters on Sludge Accumulation on Membrane Surfaces in a Submerged Membrane Bioreactor. Desalination, 151, 185-194.

Hach (1996) Hach DR/4000 Spectrophotometer Procedures Manual; Hach Company: Loveland, Colorado.

Holler, S.; Trosch, W. (2001) Treatment of Urban Wastewater in a Membrane Bioreactor at High Organic Loading Rates. J. Biotechnol., 92, 95-101.

McInnis, A. (2003) Membrane Bioreactor Testing at Reduced SRT for King County, WA. Proceedings of the AWWA Membrane Technology Conference, Atlanta, Georgia, March 2-5; American Water Works Association: Denver, Colorado.

Le-Clech Pierre, C. V.; Fane, T. (2006) Fouling in Membrane Bioreactors Used in Wastewater Treatment. J. Membr. Sci., 284, 17-53.

Livingston, D. (2003) Achieving Ultimate Nutrient Removal (UNR) Using MBR Technology. Membrane Bioreactor Workshop, Vol. VII; Enviroquip, Inc. Held at the 76th Annual Water Environment Federation Technical Exposition and Conference, Los Angeles, California, Oct. 11-15; Water Environment Federation: Alexandria, Virginia.

Trussell, S.; Merlo, R.; Hermanowicz, S.; Jenkins, D. (2006) The Effect of Organic Loading on Membrane Fouling in a Submerged Membrane Bioreactor Treating Municipal Wastewater. Water Res., 40, 2675-2683.

van der Roest, H. F.; Lawrence, D. P.; van Bentem, A. G. N. (2002) Membrane Bioreactors for Municipal Wastewater Treatment; IWA Publishing: London. 